\title{
Effect of microstructure on oxygen rich layer evolution and its impact on fatigue life during high-temperature application of $\alpha / \beta$
}

\section{titanium}

Daniel P. Satko ${ }^{\text {a1 }}$ Joshua B. Shaffer $^{\mathrm{a}}$, Jaimie S.Tiley ${ }^{\mathrm{b}}$, S.LeeSemiatin ${ }^{\mathrm{b}}$, Adam L. Pilchak ${ }^{\mathrm{b}}$, Surya R. Kalidindi ${ }^{\mathrm{c}}$, YojiKosaka ${ }^{\mathrm{d}}$, Michael G.Glavicic ${ }^{\mathrm{e}}$, Ayman A. Salem ${ }^{\mathrm{a}}$

${ }^{a}$ Materials Resources LLC, 714 E Monument Ave, Suite 130, Dayton, OH 45402, USA

${ }^{\mathrm{b}}$ Air Force Research Laboratory, Materials and Manufacturing Directorate, Wright-Patterson AFB, OH, USA

${ }^{c}$ Woodruff School of Mechanical Engineering, Georgia Institute of Technology, Atlanta, GA 30332, USA

d TIMET Henderson Technical Lab, Henderson, NV 89015, USA

${ }^{\mathrm{e}}$ Rolls-Royce Corporation, Indianapolis, IN 46206, USA

${ }^{1}$ Corresponding author: +1(937)531-6660, dan.satko@icmrl.net 


\begin{abstract}
The near alpha titanium alloy, Ti-6424S, is utilized in manycritical high-temperature aerospace components due to its unique properties. However, oxygen ingress during elevated-temperature exposure induces formation of a subsurface brittle oxygen-rich layer (ORL), resulting in a deterioration of mechanical performance. This paper, for the first time, establishes the effect of the underlying microstructure on the formation and evolution of the ORL in $\alpha / \beta$ titanium alloys.In addition, models were developed to predict (i) the evolution of ORL as a function of the material microstructure, (ii) the effect of ORL on the critical strain for in-service crack initiation, and (iii) estimates of fatigue life of components made from a specific microstructure during in-service high temperature exposure and formation of ORL. In particular, five different microstructures wereproducedby tailored heat-treatments and thermally exposed at $650^{\circ} \mathrm{C}$ up to $420 \mathrm{hrs}$. The base metal and the ORL were quantified using microhardness indentations, optical microscopy, and scanning electron microscopy (electron backscatter diffraction (EBSD), backscattered electron (BSE), and secondary electron (SE) imaging). The effective diffusion coefficients ( $\left.\mathrm{D}_{\text {eff }}\right)$ for each microstructure were calculated and then integrated into a critical strain model to predict crack initiation strain as a function of exposure time. The predicted ORL thickness was used to estimate fatigue life using experimentally measured crack growth data. The largest $\mathrm{D}_{\text {eff }}$ coefficient was observed in a colony microstructure, whilea basketweave microstructure showed the smallest $\mathrm{D}_{\text {eff. }}$ For several bimodal microstructures, $\mathrm{D}_{\text {eff }}$ was noted to increase with increasing area fraction of secondary alpha colonies.
\end{abstract}

\title{
Key Words
}

Oxygen-rich layer; alpha case; $\alpha / \beta$ titanium alloys; lifing; thermal protection systems 


\section{Introduction}

A unique combination of excellent mechanical and physical properties, including high static and fatigue strengths, low density, corrosion resistance, weldability, and excellent high temperature strength, make titanium alloys ideal candidates for critical jet-engine components[1], with the potential weight benefit in hot structures of jet engines offered by the high specific properties of near-alpha titanium alloys causing increased interest in raising the temperature tolerance of the alloys. These properties also make titanium alloys good candidates for metallic thermal protection systems (TPS)[2,3]. However, rapid diffusion of oxygen into exposed surfaces at service temperatures above $600^{\circ} \mathrm{C}$ results in a brittle sub-surface oxygen rich layer (ORL) with detrimental effects on fatigue and fracture properties by affecting slip character under load[4]. Although the maximum oxygen solubility in the alpha and beta phase is $\sim 33.9$ at. $\% \mathrm{O}$ and 3.8 at $\% \mathrm{O}$, respectively[5,6], an oxygen concentration of $0.51 \mathrm{wt} \%$ has been shown to increase the long crack growth rate by 5 to 10 times $\left(\Delta \mathrm{K}<12 \mathrm{MPa}-\mathrm{m}^{1 / 2}\right.$ for $\left.\mathrm{R}=0.01\right)$ [7]. Even small oxygen concentrations (0.06-0.18 wt $\%)$ have been observed to have deleterious impact on crack growth behavior[8]. Research simulating service-induced oxygen ingress and its effect on quasi-static and cyclic loading of Ti-6Al-2Sn-4Zr-2Mo by Pilchak et al.[4]showed that both tensile elongation to failure and fatigue life were severely deteriorated by the ingress of oxygen. It is worth noting that $3 \mathrm{D}$ atom probe tomography by Rugg et al[9]revealed that high temperature exposure introduced both oxygen and nitrogen into the subsurface layer. However, Gaddam et al.[10]found that the amount of nitrogen was below the detection limit of the electron probe micro-analyzer (EPMA). Although diffusivity data of nitrogen in Ti6242S is limited, the rate of diffusion in pure titanium is approximately two orders of magnitude slower that for oxygen[11,12], with alloys Ti6A14V and Ti6242S showing additional retardation of diffusion compared to pure titanium[13,14]As such, the brittle/hard subsurface layer at in-service 
temperatures is considered rich in oxygen, and this layer isreferred to hereafter as an oxygen rich layer (ORL).

Enhancing jet engine efficiency and avoiding failures during service requires accurate estimates of life expectancy under simulated loading conditions. Deriving such estimates from computer simulations may reduce the cost of experimental testing for component materials. Two types of families of models can be used: the first consisting of models predicting the evolution of the ORL under various environmental conditions of service temperatures and exposure time, and the second including models that capture the effect of the ORL thickness on the mechanical properties (including tensile ductility and fatigue life).

A number of efforts have been devoted to the first type of models that predict the evolution of the ORL by modeling oxygen diffusion in $\alpha / \beta$ titanium alloys[15-18]. In these models, the thickness of the ORL is assumed to be small compared to the thickness of the bulk, allowing the application of Fick's second law of diffusion to estimate the oxygen concentration profile and concomitant ORL thickness at various temperatures and exposure durations[19]. Many of these efforts utilize experimental data and/or simulations to calibrate Fick's second law diffusion coefficient $[15-18,20]$. An excellent summary of oxygen diffusivity in various titanium alloys has been provided by Liu and Welsch[21]. However, the absence of consistent accounting for the effect of microstructure (including both morphology and crystallography) reduces the practical implementation of the results across various microstructures for the same alloy. In addition, the emergence of jet-engine components with location-specific tailored microstructures for optimized performance (e.g. turbine disks with gradient microstructures, blisks, etc.) further highlights the need for microstructure-specific estimation of oxygen ingress. Recent work by 
Tiley et al[22] confirmed the impact of morphological orientation of alpha laths on oxygen ingress in Ti-6424S with colony microstructure.

The large variability of microstructures in $\alpha / \beta$ titanium alloys[23]makes it difficult to extract unique trends in diffusion modeling parameters directly from published literature., In particular, analysis of the Arrhenius plots given by McReynolds et al.[18]gives an estimated diffusion coefficient of a Ti-6242Ssample with a bimodal microstructureof $\sim 4 \times 10^{-3} \mu \mathrm{m}^{2} / \mathrm{s}$ at $649^{\circ} \mathrm{C}$, based on optical measurements of ORL thickness. This is approximately 20 times higher than the value reported by Shamblen and Redden[17] at $639^{\circ} \mathrm{C}\left(\mathrm{D}_{\left(639^{\circ} \mathrm{C}\right)} \approx 2 \times 10^{-4} \mu \mathrm{m}^{2} / \mathrm{s}\right)$, which is close to the diffusion coefficient reported for pure alpha titanium $\left(2.105 \times 10^{-4} \mu \mathrm{m}^{2} / \mathrm{s}\right)$ by Brockman et al.[20], who used a representative volume element (RVE) approach and 2dimensional FEM simulations based on electron backscatter diffraction data to simulate oxygen diffusion in microstructure constituents of Ti-6242S with a globular microstructure. In that work, separate diffusion coefficients were used for the alpha phase $\left(\mathrm{D}_{\alpha\left(649^{\circ} \mathrm{C}\right)}=2.105 \times 10^{-4} \mu \mathrm{m}^{2} / \mathrm{s}\right)$, beta phase $\left(\mathrm{D}_{\beta\left(649^{\circ} \mathrm{C}\right)}=5.765 \times 10^{-4} \mu \mathrm{m}^{2} / \mathrm{s}\right)$, and alpha/beta boundary $\mathrm{D}_{\alpha / \beta\left(649^{\circ} \mathrm{C}\right)}=10^{5} \mathrm{D}_{\alpha\left(649^{\circ} \mathrm{C}\right)}$. The model calibration was conducted using electron probe microanalysismeasurements of oxygen distribution after exposure at $650^{\circ} \mathrm{C}$.Although the materials used in Refs.[18] and [20] were the same alloy (Ti-6242S), the calibrated model parameters were different, possibly due to the difference between bimodal and globular microstructures and/or the procedures used to experimentally measure the ORL thickness experimentally.

Estimation of the effect of ORL thickness on the mechanical behavior of titanium alloys has been the subject of many research projects[16,21,24,25]. In particular, Parthasarathy et al. proposed a life prediction model based on the work of Hutchinson and Suo[26] and Thouless et al.[27] accounting for crack formation in the brittle ORL on the surface of Ti-6242S samples 
subjected to a time-temperature-environment cycle[16]. The model was linked to an oxygendiffusion model to predict the depth of the ORL. The oxygen diffusion model was calibrated using the diffusivity of oxygen in beta titanium. However, at the temperature investigated in the paper $\left(650^{\circ} \mathrm{C}\right)$, the alloy consisted of mainly alpha phase with less than $10 \%$ retained beta[21]. As such, a more accurate diffusivity value based on the underlying microstructure in the sample may have provided different results. Phase volume fraction variations with temperature and their effect on the mechanical properties of $\alpha / \beta$ titanium alloys were established by Liu and Welsch[21], who concluded that high bulk oxygen levels of $0.65 \mathrm{wt} \%$ embrittled the alpha phase with no embrittlement of the beta phase. Gurappa[25] postulated an equivalent life model based on variation of ORL thickness after exposure at temperatures from $600^{\circ} \mathrm{C}-900^{\circ} \mathrm{C}$ for another high-temperature alloy, IMI834. However, since temperature transients are common during service, the lifing of the component based on oxygen ingress should be linked to the accumulative depth of the ORL at various temperatures.

Although most of the above mentioned efforts succeeded in fitting diffusion models to specific sets of experimental measurements of ORL, discrepancies were noted in the estimates of diffusion coefficients. These discrepancies directly impacted the fidelity of the mechanicalproperty predictions. Such discrepancies may arise from (i) a lack of consistency in accounting for the microstructure (morphological and crystallographic information) within the same alloy, (ii) the lack of reproducibility/repeatability between various techniques to quantify the depth of the ORL, (iii) the limited information available on the interplay between various diffusion coefficients for alpha-phase, beta-phase, and the interfaces between them, and (iv) the misuse of "alpha case" terminology to describe the ORL occurring in-service which,in the authors' view, is important for differentiating between a high temperature phenomenon observed during casting 
(above $\beta$ transus) and thermomechanical processing close to or above the $\beta$ transus (with a high volume fraction of beta phase which and controlled by oxygen diffusivity in $\beta$ ) leading to an obvious layer of hard globular $\alpha$ (different than the base metal microstructure) beneath the surface resulting in the known alpha-case and the phenomenon occurring during heating the material at moderate in-service temperatures below the $\beta$ transus, resulting in a subsurface hard layer with an alpha phase volume fraction that is similar to the base metal and controlled by oxygen diffusion in $\alpha, \beta$ and $\alpha / \beta$ interfaces..

In order to overcome these shortcomings, the following workflow wasdesigned and executed as follows: (i) Ti-6242S samples with various starting microstructures were used to capture the impact of microstructure on the depth of ORL after various exposure times; (ii) a protocol to measure the depth of the ORL based on microhardness measurements was employed; (iii) an effective diffusivity of each microstructure (instead of individual diffusivities for individual constituents) was determined based on modified Fick's second law, utilizing hardness measurements as an indicator of oxygen concentration; and (iv) the estimated effective diffusivity values were implemented into lifing models to demonstrate the integration of various material models accounting for microstructure spatial variability. Using the above, a protocol to account for the impact of oxygen ingress on the lifing of titanium alloys (with a location specific microstructure) during high temperature service was proposed.Finally, some discussion is also dedicated to providing a clarifying framework for the difference of terminology between ORL and alpha-case based on the differences in microstructure and phase composition during and after oxygen ingress, with an emphasis on the parameters to be used in each case. 


\section{Materials and Experimental Procedures}

The overall strategy of this study involved production of differing microstructures using various heat treatments which were subsequently subjected to controlled oxidation testing. The resulting materials were characterizedto investigate the ORL by etched optical measurements and microhardness profiling. The near alpha alloy Ti-6242S was chosen due to its widespread use in high temperature applications where property debit due to oxygen ingress is a critical concern. Typical chemical composition of Ti6242S (in weight percent) is $6 \% \mathrm{Al}, 2 \% \mathrm{Sn}, 4 \% \mathrm{Zr}, 2 \% \mathrm{Mo}$ and about $0.1 \% \mathrm{Si}$ with the balance being titanium[28] .The as-received material consisted of five $4.4 \mathrm{~mm}(0.18 \mathrm{inch})$ thick sheetswith dimensions $147 \mathrm{~mm} \times 147 \mathrm{~mm}$ ( 6 inch $\times 6$ inch), in a mill-annealed condition with a microstructure consisting of mostly globular alpha with $\sim 15 \%$ transformed beta and a beta transus of $988^{\circ} \mathrm{C}\left(1810^{\circ} \mathrm{F}\right)$. In addition to the as-received (millannealed) microstructure, four heat treatments were conducted to produce other types of microstructures: (1)air cooling from above the beta transus, giving a colony microstructure with coarse lamellae; (2) quenching from above the beta transus, giving a basketweave microstructure with fine laths; $(3,4)$ duplex annealing giving two different bimodal microstructures with approximately $35 \%$ and $45 \%$ primary alpha. Heat treatments were conducted in a vacuum furnace from the mill-annealed condition, except for the quenched sample, which was heattreated in air prior to quenching.

Characterization of the heat-treated samples was performed using backscattered electron (BSE) imaging and electron backscatter diffraction (EBSD) in a TESCAN VEGA3 scanning electron microscope equipped with a Bruker EBSD detector operating at $25 \mathrm{kV}$. The beam current for EBSD data collection was set at 11nA. The morphology and spatial distributions of various constituents were revealed in BSE images for all five microstructures (Figure 1) while the 
crystallographic texture was captured in inverse pole figure maps and pole figures (Figure 2).Large-area EBSD scans of $2.5 \mathrm{~mm} \times 2.5 \mathrm{~mm}$ were conducted for the basketweave and colony microstructures in order to capture multiple prior beta grains. As each of the five microstructures studied was created from a common (i.e. mill-annealed) parent sample, similar texture components are present in each sample, minimizing any texture effect on oxygen ingress and subsequent characterization.

Figure 1- Backscattered electron images of Ti 6242S with various microstructures: (a) Basketweave, (b) Colony, (c) Bimodal $\left(\sim 35 \% \alpha_{p}\right)$, (d) Bimodal $\left(\sim 45 \% \alpha_{p}\right)$, and (e) Mill-annealed $\left(\sim 85 \% \alpha_{p}\right)$.

Figure 2 - Inverse pole-figure maps and pole-figuredata from EBSD for Ti $6242 \mathrm{~S}$ with various microstructures: (a) Basketweave, (b) Colony, (c) Bimodal I ( $\left.\sim 35 \% \alpha_{p}\right)$, (d) Bimodal II ( $\left.\sim 45 \% \alpha_{p}\right)$, and (e) Mill-annealed $\left(\sim 85 \% \alpha_{\mathrm{p}}\right)$.Inverse pole figure maps are displayed along the indentation (rolling) direction. The length of the scale bar is $250 \mu \mathrm{m}$.

\subsection{Thermal Exposure}

Prior to thermal exposure, test coupons from each microstructure were sectioned using abrasive waterjet cutting and then mechanically ground to 1200 grit to remove any ORL or alpha case created during previous thermomechanical processing steps. Isothermal oxidation experiments were then conducted in air at $650^{\circ} \mathrm{C}$ for $9,25,118$, and 420 hours using a laboratory box furnaceto enablequantification of the evolution of the depth of oxygen ingress for different microstructures. The rectangular samples were positioned on an insulating brick resting on one of the transverse faces, ensuring uniform exposure to the furnace atmosphere across the normal (plan) faces (corresponding to the original sheet top and bottom faces).The dimensions of each coupon were measured before oxidation and the weight was recorded before and after thermal exposure to calculate the weight gain due to oxygen ingress.

Figure 3 - Positioning of sample coupons during thermal exposure. The labels RD, TD, and ND denote the rolling, transverse, and normal directions of the sheet, respectively. 


\subsection{Measuring Depth of Oxygen-Rich Layer (ORL)}

Two methods were used to quantify the depth of ORL and to establish protocols for repeatability and reproducibility; namely, optical microscopy of tint-etched surfaces and spatially distributed microhardness indentations.

\subsubsection{Optical Microscopy}

Samples were sectioned along the longitudinal plane to reveal a cross-section of the ORL (Figure 4), mounted in epoxy,and metallographically prepared by mechanical grinding and polishing followed by vibratory polishing to produce a deformation-free surface. A bright layer highlighting the ORLwas produced by immersion for 9 seconds in an oxalic acid tint etchant consisting of $2 \mathrm{~mL} \mathrm{HF}$ and $98 \mathrm{~mL}$ saturated aqueous $\mathrm{C}_{2} \mathrm{H}_{2} \mathrm{O}_{4}$, which was measured optically to give an estimated ORL thickness[29]. While this data was not used for subsequent analysis of the rate of oxygen diffusion in each microstructure, it is often seen in the literature [10,29]and is useful for comparison between techinques. In order to quantify the oxygen ingress depth objectively, an image processing technique shown in Figure 5(a) was applied consisting of the following steps:

1. Contrast enhancement producing a thin line of saturated pixels at the sample surface

2. Creation of a depth-sensitive histogram by horizontal summation of gray-level over the image width (i.e., parallel to sample surface)

3. Extracting ingress depth as full width at half maximum (FWHM) of the peak in the brightness distribution corresponding to the bright tint-etched area (green dashed lines in Figure 5a). The height of this peak is referenced to the average intensity of the base metal in the image area. This is the vertical dashed line in Figure 5a

Figure 4 - Sectioning coupons for characterization of ORL depth Figure 5 - Measuring Oxygen Ingress Depth: (a) Optical microscopy using FWHM of the DepthSensitive Histogram (b) Microhardness Indentation. Average oxygen counts as a function of depth from the surface across a $75 \mu \mathrm{m}$ width scan area are given for comparison. 


\subsubsection{Hardness measurements}

To establish an automated procedure for measuring the depth of oxygen ingress using hardness as a proxy for oxygen concentration, Vickers microhardness profile measurements with a $25 \mathrm{gf}$ load wereperformed. The width of the resultant indents was approximately 10 microns. The profile was measured for each microstructure for a depth from the surface of 100 microns with additional indents performed at $100 \mathrm{gf}$ at greater depths to establish the base metal hardness. Due to the small diagonal length of the indentations, image processing of indentation captured by secondary electron images of the indented surface were used to provide an accurate measure of indent size. The hardness was calculated using[30]:

$$
H V=\frac{2 F \sin \left(\frac{136}{2}\right)}{d^{2}}
$$

where $F$ is applied force, and $d$ is the average diagonal length of the indentation.

The hardness value decreased with depth (i.e. decreasing oxygen concentration), giving the ingress depth at the transition point between the ORL and the base metal hardness (see Figure 5b), which corresponds to the transition between ORL and base metal oxygen concentration.

Minimization of the texture effect on the value of hardness and depth of the ORL was an important consideration in experimental design, and was accomplished by maintaining a constant relationship between the allowed ingress direction, indentation direction, and the significant texture components (Figure 2). Additionally, multiple rows of indentations were spaced at wide intervals ( $>50 \mu \mathrm{m}$ between neighboring indentations) to minimize the effect of local (i.e. $<20 \mu \mathrm{m}$ ) heterogeneity of microstructure[22]. 
In addition to the indentation depth traces performed on the transverse section, indentations were also performed on the plan (ingress) surface at $15 \mathrm{gf}, 25 \mathrm{gf}$, and $100 \mathrm{gf}$ on samples exposed for $118 \mathrm{hr}$ and $430 \mathrm{hr}$ to evaluate the assumption of a fixed surface oxygen concentration required for Fick's second law analysis.

\section{Modeling Approach}

\subsection{Analysis of oxygen diffusion}

The thickness of the oxygen-rich layer is usually small compared to typical component dimensions leading to a reasonable assumption of a fixed bulk oxygen concentration[16,17,29,31]. Fick's second law is usually expressed as

$$
\frac{\partial C}{\partial t}=D \frac{\partial^{2} C}{\partial z^{2}}
$$

where $z$ is the distance from the surface and $C$ is concentration. The relation was applied here to describe the development of the oxygen-rich layer upon exposure to elevated temperature. Under boundary conditions of fixed concentrations in the bulk and at the interface between the metal and thin adherent stoichiometric metal oxide $\left(\mathrm{TiO}_{2}\right)$ layer[17,32,33], a solution to Equation 2 is given by[19]:

$$
\left[1-\frac{C-C_{o}}{C_{s}-C_{o}}\right]=\operatorname{erf}\left(\frac{z}{2 \sqrt{\left(D_{T} t\right)}}\right)
$$

giving the oxygen concentration, $C$, at any distance, $z$, from the metal-metal oxide interface after exposure for time, $t$,at temperature, $T$, where $C_{S}$ and $C_{0}$ are the surface and bulk material oxygen concentrations, respectively. Using an observed direct proportional relationship between oxygen content and hardness at low concentrations, Rosa[6]proposed the following modified solution using hardness to describe the gradient: 


$$
\frac{H(z)-H_{0}}{H_{S}-H_{0}}=1-e r f\left(\frac{z}{2 \sqrt{D_{T} \cdot t}}\right)
$$

Calibration of experimental measurements to Eq. (4) using nonlinear regression allows an estimation of the effective (homogenized) diffusion coefficient $D_{T}$ for each exposure temperature, $T$.

As a thermally activated process, the variation of the diffusion coefficient with temperature can be further described by an Arrhenius rate equation as

$$
D_{T}=D_{o} e^{-Q / R T}
$$

where $D_{o}$ is the pre-exponential constant, $\mathrm{Q}$ is the activation energy, and $\mathrm{R}$ is the universal gas constant. Evaluating $D_{T}$ at various temperatures allows for an estimate of the value of Q[29].

In order to account for the inherent heterogeneity in the $\alpha-\beta$ microstructures, the calibrated values of the diffusion coefficient have been assumed to represent an effective (homogenized) value for individual microstructures, incorporating all of the mesoscale details of the microstructure (e.g., grain morphology and crystallography, grain and phase boundaries).

\subsection{Prediction of Surface Crack Initiation in the ORL}

Due to the formation of the brittle ORL on Ti-6424S surfaces, the material response of the samples to mechanical loading was compared to the behavior of a composite material for predicting elastic and plastic properties[34]. The degradation in the mechanical behavior of Ti$6424 \mathrm{~S}[4,16]$ due to the brittle ORL is similar to other materials with hard surface layers including nitride steel and chromium-plated copper where surface cracks are formed across the brittle ORL under tensile loading[34]. Consequently, the following effects are assumed to occur based on the presence of the brittle ORL[4,34] : 
(a) Increasing the thickness of the ORL decreases the ductility.

b) Formation of surface cracks in early stages of tensile testing is equivalent to introducing notches before testing.

(c) The thickness of the brittle ORL affects the mechanical behavior in a manner similar to a notch of the same depth.

Figure 6 (a) Schematic of surface cracks in the brittle ORL under tensile loading; (b) Secondary electron image showing periodic cracking orthogonal to the loading direction

The critical tensile strain to initiate cracks on the surface of ORL of Ti-6424Swas predicted using the thickness of the ORL[16]. In particular, the thickness of the ORL (w) (Figure 6), as measured using microhardness data, was used to estimate the critical stress for crack initiation in the ORL $\sigma_{O R L, c r i t}$ as:

$\sigma_{O R L, c r i t}=\left[\frac{3 \Gamma \tau E_{O R L}}{2 w}\right]$

where $\Gamma$ is the fracture energy per unit area of the ORL (estimated as $\left.300 \mathrm{~J} / \mathrm{m}^{2}[16]\right), \tau=$ $448 M P a=\left(0.47 * \sigma_{Y}\right)$ is the shear stress at the ORL/base metal interface, and $E_{w}=110 \mathrm{GPa}$ is the Young's modulus of the embrittled ORL[16].

The critical applied strain to initiate a crack in the ORL was provided by

$\varepsilon_{\text {crit }}=\left(\sigma_{O R L, \text { crit }}+\sigma_{O R L, \text { resid }}\right) / E_{w}$

where $\sigma_{O R L, \text { resid }}$ is the compressive residual stress due to the expansion of Ti lattice from oxygen ingress. Due to a lack of property data in the ORL, an upper bound on the residual stress is assumed setting it equal to $\sigma_{Y}=950 \mathrm{MPa}[16]$. Figure 7 shows model predictions which are consistent with Ref [16]. 
Figure 7 - Predicted critical strain to nucleate surface cracks in the ORL under tensile loading. The model parameters and data were obtained from Ref [16].

\subsection{Lifing Using Crack Growth}

Parthasarathy et al.[16] and Pilchak et al.[4]showed that cracking of the ORL can occur during elastic loading and that the cracks penetrate through the embrittled layer until encountering the underlying ductile base metal which is able to arrest the crack. Pilchak et al.[4]also noted a reduction in fatigue life scatter due to the presence of an oxygen-enriched, embrittled layer. This is because the depth of the oxygen ingress and thus the embrittling effects were well controlled by the exposure process; therefore a "precrack" the depth of the ORL was formed on the first cycle. Thus, one can assume that a crack having a depthequal to the ORL is formed on the first cycle and then rely on deterministic, linear elastic fracture mechanics predictions to calculate the remaining useful life time.

In this framework, the total lifetime depends primarily on the long-crack growth rates which are driven by the stress intensity range $(\Delta \mathrm{K})$ at the crack tip. This inherently assumes that the oxygen ingress depth is sufficiently deep that the crack formed produces a $\Delta \mathrm{K}>\Delta \mathrm{K}_{\mathrm{th}}$ (the threshold stress intensity range for a long crack). If $\Delta \mathrm{K}<\Delta \mathrm{K}_{\mathrm{th}}$ the crack may still grow, but probabilistic predictions which incorporate microstructural effects should be utilized.

Here, the modeled ORL thickness was used as a function of time for colony microstructure as initial crack sizes in crack growth lifetime predictions performed over a range of stresses relative to the yield stress. The model assumes a through-crack in a rectangular plate of dimensions $25 \mathrm{x}$ $25 \mathrm{~mm}$ subjected to constant amplitude fatigue loading at $\mathrm{R}=0.1$. The number of cycles to failure, $\mathrm{N}_{\mathrm{f}}$, is calculated as:

$N_{f}=\int_{a i}^{a f} \frac{d a}{\left(\frac{d a}{d N}\right)}$ 
Where $a_{i}$ and $a_{f}$ are the initial and final crack sizes, respectively, with the latter being defined as the crack length at which $\Delta \mathrm{K}>\Delta \mathrm{K}_{\mathrm{IC}}$ (the mode-I fracture toughness of the material). The crack growth rate, da/dN, was interpolated from a look-up table for a Ti-6242 alloy with similar microstructure[35]. The growth rate of cracks when $\Delta \mathrm{K}<\Delta \mathrm{K}_{\mathrm{th}}$ utilized the small crack data of Jin and Mall[36]. The stress intensity range, $\Delta K$, is the difference between $K_{\max }-K_{\min }$ where $K=$ $\mathrm{F} \sigma(\pi \mathrm{a})^{1 / 2}$ and $\mathrm{F}$ is a shape factor that depends on the crack geometry (a surface, through-crack here)[37].

\section{Results and Discussion}

\subsection{Experimental Observations}

The change in the mass of each sample after thermal exposure gives a qualitative estimate of the degree of oxygen uptake in the surface oxide scale and in the ORL. The mass change data are shown inFigure 8normalized by the exposed surface area of each sample. A significant variation is noted, with the colony and basketweave microstructures exhibiting the highest and lowest weight gains, respectively. Optical measurements of ORL thickness after 420 hours show good correlation with the trends given by the weight gain measurements (Figure 8). Microhardness traverse data (Figure 8) also show good agreement with the trends noted in both the weight gain and optical measurements of ORL thickness with respect to sample microstructure, demonstrating the utility of using microhardness measurements to delineate the presence and extent of an ORL. Figure 9 shows the microhardness trace data for each of the five microstructures. The data is normalized according to Equation 4 to account for variation in base metal hardness for the different microstructures. In every case, there are significant differences between the colony, basketweave, and mill-annealed (globular) microstructures. 
A key assumption made in using Fick's second law to model the oxygen ingress behavior is the existence of a constant oxygen concentration at the metal-metal oxide interface[32,33].

Indentations made on the exposed surface (Figure 10) indicate very little change in hardness and, by extension, oxygen concentration in the near-surface layer from $118 \mathrm{hr}$ to $430 \mathrm{hr}$ of exposure. It worth noting that there was insignificant change in the hardness values between $15 \mathrm{gf}$ and $25 \mathrm{gf}$. However there was a pronounced drop in the hardness at 100gf, which was noted to be greater at shorter exposure time (corresponding to shallower ORL) and decreased at longer exposure time (corresponding to deeper ORL). According to the expanding cavity model of Johnson for indentation in elastic-plastic materials[38,39], the size of the plastic zone beneath the indenter scales proportionally to the contact radius (i.e. core size) of the indentation $(\sim 7.5 \mu \mathrm{m}$ at $100 \mathrm{gf}$ vs. $\sim 2.5 \mu \mathrm{m}$ at $15 \mathrm{gf})$. The observed drop in hardness with increased indentation load is likely attributable then to the increased volume of the plastic zone, which increases the contribution of the softer base metal beneath the ORL. The hardness drop was less pronounced after $420 \mathrm{hr}$ because the ORLthickness is increased at longer exposure time,reducing the contribution from the softer base metal. It is also worth noting that the difference in observed surface hardnessbetween the two microstructures is proportional to the base metal hardness (402HV25g vs. $358 \mathrm{HV} 25 \mathrm{~g}$ for the basketweave and bimodal, respectively). The normalized surface harness values for the basketweave and bimodal microstructures are 2.43 and 2.42 at $118 \mathrm{hr}$ exposure and 2.33 and 2.45 at $430 \mathrm{hr}$ exposure, respectively, validating the constant $C_{S}$ assumption.

Figure 8 - Comparison of optical and microhardness measurements of ORL thickness with weightgain data after $420 \mathrm{hr}$ exposure.

Figure 9 - Measured hardness profile for various microstructures, normalized according to Equation 4 to account for variation in base metal hardness between microstructures. Figure 10 - Indentation hardness measurements under loads of 15gf, 25gf, and 100gf on the exposed surface for the bimodal microstructure with $45 \% \alpha_{P}$ and the basketweave microstructure. Error bars indicate the standard deviation of 5 duplicate indentations per sample and force. 
4.1.1 Stability of Microstructure during Thermal Exposure

It is necessary to evaluate the stability of the different phases during thermal exposure in order to successfully implement models developed using the collected data and thereby populate a database suitable for microstructure/oxygen ingress linkages. To accomplish this, test samples were removed from the furnace after 4 hours and water quenched. The samples were sectioned and examined using BSE imaging for comparison with micrographs taken prior to thermal exposure to look for any changes in the bulk microstructure attributable to thermal effects other than oxygen ingress (Figure 11). Image segmentation using TiSeg $^{\mathrm{TM}}$ [40] showed no significant difference in volume fractions of alpha and beta phases, or primary and secondary alpha in the case of the duplex annealed samples (Table 1). Also lacking from the micrographs is the presence of fine Widmanstatten structure developed by the transformation of excess beta during quenching from the alpha+beta region of the phase diagram. This stability in microstructure is expected for the exposure temperature of $650^{\circ} \mathrm{C}$ due to the flatness of the beta approach curve at the exposure temperature[41].

Figure 11-BSE images of the microstructure of the bimodal microstructure with $35 \%$ primary alpha as-heat treated (left) and after $4 \mathrm{hr}$ at $650 \mathrm{C} / \mathrm{WQ}$ (right) showing the stability of microstructure at the exposure temperature

Table 1 - Metrics for bimodal and mill-annealed microstructures as-heat treated, after $4 \mathrm{hr}$ at $650 \mathrm{C}$ followed by water quenching(WQ), and after $420 \mathrm{hr}$ thermal exposure at $650^{\circ} \mathrm{C}$

\begin{tabular}{|l|l|l|l|l|l|l|l|l|l|}
\hline Microstructure & \multicolumn{3}{|l|}{ As-heat treated } & \multicolumn{3}{l|}{4 hours at $6500^{\circ} \mathrm{C} / \mathrm{WQ}$} & \multicolumn{3}{l|}{420 hours at $650^{\circ} \mathrm{C}$} \\
\hline & $\alpha_{P}(\%)$ & $\alpha_{S}(\%)$ & $\beta(\%)$ & $\alpha_{P}(\%)$ & $\alpha_{S}(\%)$ & $\beta(\%)$ & $\alpha_{P}(\%)$ & $\alpha_{S}(\%)$ & $\beta(\%)$ \\
\hline Bimodal I & 37.8 & 46.3 & 16.2 & 39.5 & 49 & 10.5 & 45.8 & 44.5 & 10 \\
\hline Bimodal II & 44.3 & 38 & 18 & 44 & 43 & 13 & 50.5 & 38.8 & 11.3 \\
\hline Mill-anneal & 84.3 & 2 & 14 & 87.3 & 2.3 & 9.7 & 92.5 & 1.3 & 5.8 \\
\hline
\end{tabular}


4.1.2 Stability of Microstructure in the ORL

The microstructure in the ORL is also noted to be little changed with respect to the as-heat treated condition in spite of the presence of increased oxygen concentration (as indicated by microhardness measurements), as shown by micrographs taken at the surface before and after thermal exposure (Figure 12) and the data given in Table 1. A 6-8\% increase in volume fraction of $\alpha_{P}$ is noted after $420 \mathrm{hr}$ exposure. While oxygen is a powerful alpha stabilizer, the relatively low temperature of thermal exposure relative to the beta transus is expected to result in little excess globular alpha characteristic of an "alpha case", as described in more detail later.

Figure 12-BSE images of the bimodal microstructure with $45 \%$ primary alpha as received (top) and in the ORL after $420 \mathrm{hr}$ at $650^{\circ} \mathrm{C}$ (bottom) showing the slight increasein primary alpha in the ORL.

\subsection{Model application}

An oxygen diffusion model was developed incorporating hardness measurements, temperature, exposure time, and microstructure to predict the depth of ORL. This required calibrating an effective diffusion coefficient $\left(\mathrm{D}_{\text {eff }}\right)$ for each microstructure. The predicted depth of ORL was then used to predict the critical strain for surface cracking under tension using Equation 7 described in section 3.2 .

\subsubsection{Oxygen Diffusion Model}

Application of the effective diffusion model to the measured microhardness traces provided values for the effective diffusion coefficients for oxygen in each of the five microstructures considered (Table 2). The basketweave microstructure is found to have the lowest diffusion coefficient, with an effective diffusion coefficient only $18 \%$ higher than that for pure alpha phase[20]. The calculated diffusion coefficient for the colony microstructure is more than quadruple that of the basketweave, with the other microstructures in agreement with results given by other techniques (e.g., optical and weight gain). Compared to the as-received (mill-annealed) 
condition, the diffusion coefficient was reduced by $32 \%$ upon heat treatment to the basketweave microstructure and increased significantly for all other heat treatments.

Table 2 - Effective Diffusion Coefficients Calculated from Hardness Profiles

\begin{tabular}{|l|l|c|c|c|}
\hline $\begin{array}{l}\text { Sheet } \\
\text { ID }\end{array}$ & Microstructure & $\mathbf{D}_{\text {eff }}\left(\mu \mathrm{m}^{2} / \mathrm{s}\right)$ & $\mathbf{D}_{\text {eff }} / \mathbf{D}_{\boldsymbol{\alpha}}$ & $\begin{array}{l}\mathbf{D}_{\text {eff }} \mathbf{D}_{\text {eff (Mill- }} \\
\text { annealed) }\end{array}$ \\
\hline Sheet 1 & Basketweave with fine laths & $2.48 \mathrm{E}-04$ & 1.18 & 0.68 \\
\hline Sheet 2 & Bimodal I $\left(\sim 35 \% \alpha_{\mathrm{p}}\right)$ & $6.89 \mathrm{E}-04$ & 3.27 & 1.88 \\
\hline Sheet 3 & Colony with Coarse alpha laths & $1.13 \mathrm{E}-03$ & 5.37 & 3.08 \\
\hline Sheet 4 & Mill-annealed $\left(\sim 85 \% \alpha_{\mathrm{p}}\right)$ & $3.67 \mathrm{E}-04$ & 1.74 & 1.00 \\
\hline Sheet 5 & Bimodal II $\left(\sim 45 \% \alpha_{\mathrm{p}}\right)$ & $5.59 \mathrm{E}-04$ & 2.66 & 1.52 \\
\hline
\end{tabular}

Validation of the model was performed using a set of hardness measurements of Ti-6424S sheet with an equiaxed microstructure from Parthasarathy et al.[16]. Fitting these values to Equation 1 resulted in an effective diffusivity $\mathrm{D}_{\text {eff }}=2.57 \mathrm{E}-04 \mu \mathrm{m}^{2} / \mathrm{s}$, approximately 1.22 timesthe diffusion coefficient of oxygen in pure alpha phase[20].Application of the solution to the diffusion equation yielded the normalized ORL thickness as a function of the distance from the surface (Figure 13).

Table 3 - Predicted thickness of the oxygen-rich layer after $420 \mathrm{hr}$ at $650^{\circ} \mathrm{C}$

\begin{tabular}{|l|c|l|c|c|c|}
\hline & Basketweave & $\begin{array}{l}\text { Mill- } \\
\text { annealed }\end{array}$ & $\begin{array}{l}\text { Bimodal } \\
(45 \%)\end{array}$ & $\begin{array}{l}\text { Bimodal } \\
(35 \%)\end{array}$ & Colony \\
\hline ORL Thickness $(\mu \mathrm{m})$ & 31.5 & 38.3 & 47.2 & 52.5 & 67.2 \\
\hline
\end{tabular}

Figure 13-Normalized predictions of the thickness of the oxygen-rich layer using Fick's second law.

It is well known that the diffusivity of interfaces (e.g. grain boundaries or interphase boundaries) is typically several orders of magnitude higher than diffusion through the grain interior[20]. Thus, it is expected that the variation in diffusivity for various microstructures will be dominated 
by the density and alignment of interfaces relative to the exposed surface. Phase composition is expected to introduce a secondary effect, as diffusivity of the beta phase is approximately 2.7 times higher than the alpha phase[20]. This is reflected by the large increase in effective diffusivity of the colony microstructure as compared to the mill-annealed microstructure. The long, highly oriented interphase boundary network present in the colony microstructure provides a preferential pathway for oxygen ingress, leading to rapid buildup of the brittle layer.

Conversely, the mill-annealed microstructure lacks both the density and alignment of interphase boundaries, leading to slower ingress of oxygen. The performance of bimodal microstructures is mixed, showing an increase in diffusivity with increasing volume fraction of secondary alpha colonies. Of the five microstructures examined, the quenched basketweave structure was found to exhibit the lowest effective diffusivity and least depth of ingress, despite having a high density of interphase boundaries. This is likely due to the short length of boundary segments and lack of alignment as compared with the colony microstructure.

These results, for the first time, quantitatively confirm the necessity to explicitly account for the dependence of diffusion properties on microstructure when modeling the behavior of complex structures during exposure to in-service temperatures.

\subsubsection{Surface Crack Initiation/Lifing Model}

Integrating the crack initiation model (Figure 7) with the results of the oxygen ingress model

(Figure 13) provided predictions of the critical strains to nucleate cracks at different exposure times (Figure 14). The predictions in Figure 14 can be linked directly to numerical models (e.g., finite element models) as an upper limit for location specific strain to avoid cracking in high temperature service under various loading conditions, exposure times, and microstructures. 
Figure 14 - Predicted critical strain for crack nucleation as a function of exposure time at $650^{\circ} \mathrm{C}$ for various microstructures of Ti-6424S.

\subsubsection{Crack Growth Lifing Model}

The results of the deterministic crack growth calculation for colony microstructure, performed at various fractions of the yield strength of the alloy and for different initial oxygen ingress depths (i.e. initial crack size), are summarized in Figure 15. The red circles are tied to the right y-axis and top $\mathrm{x}$-axis showing the ingress of oxygen into the material as a function of time. Each ingress depth was used as the initial crack size to calculate the total cycles to failure. The life curves are not smooth; each exhibits a transition at a different initial crack size with lower applied stresses corresponding to larger transition points. This is because an initial crack size less than the transition point will produce cracks with $\Delta \mathrm{K}<\Delta \mathrm{K}_{\mathrm{th}}$, which is still of microstructurally small dimensions and has not yet developed significant closure in its wake. This is also a consequence of the change to a low ductility fracture process as described by Pilchak et al.[4]. As a result, the crack behaves as a typical small crack where it grows at accelerated rates at low $\Delta \mathrm{K}$. As the applied stress is increased, cracks with physically-small dimensions still satisfy $\Delta \mathrm{K}>\Delta \mathrm{K}_{\mathrm{th}}$ and thus the cracks may propagate directly without the need to invoke small crack effects.

Figure 15 - Results from deterministic fatigue crack growth predictions at various stress levels utilizing the oxygen-ingress depth as a function of time for Ti-6424S as the initial crack size. The transition in behavior at smaller crack lengths for each applied stress level is due to the fact that the depth of the crack formed in the ORL did not have sufficient driving force to grow as a long crack and thus small crack effects had to be considered.

\subsection{Differences Between Oxygen-Rich Layer (ORL) and Alpha-Case}

The rapid uptake and drastic effect of oxygen on the microstructure and mechanical properties of titanium alloys make it a critical interstitial solute for the alloy. The diffusion of oxygen in nearalpha and alpha/beta alloys is highly dependent on temperature, exposure time, and microstructure constituents (e.g., alpha and beta phases). As such, and due to the frequent confusion in terms present in the literature, it is prudent to provide some discussion and 
definition as to the precise definition of the oxygen-rich layer (ORL) as compared to the more frequently seen "alpha-case".

\subsubsection{Alpha-Case}

During cooling of cast, beta-worked, or beta-annealed titanium alloys, the material absorbs oxygen from the environment. Oxygen ingress starts above the beta transus with $100 \%$ beta volume fraction, resulting in a surface layer rich in oxygen. Due to the powerful alpha stabilizing effect of oxygen, the beta transus temperature of this localized surface region is increased. In alloy Ti-6A14V, this effect is approximated by: $T_{T R A N S, N E W}\left({ }^{\circ} \mathrm{C}\right)=937+242.7 *$ $w t \% O[21]$. Consequently, the oxygen-rich surface layer transforms into a continuous layer of alpha phase before the rest of the material, resulting in a characteristic brittle surface layer of continuous alpha grains that is called "alpha case" with a drastic increase in the volume fraction of alpha phase within this layer[10,42]. Efforts to model this process need only take into account the diffusivity of oxygen in the beta phase at the alloy composition due to the single-phase constitution of the material during ingress. In addition, mechanical or chemical methods are typically used to remove the hard alpha case from finished components, minimizing its contribution to the mechanical properties of components during service.

\subsubsection{Oxygen-rich layer (ORL)}

In contrast to oxygen diffusion during high temperature processes such as casting and forging, components in service are exposed to more moderate temperatures. For example, the volume fraction of beta phase in Ti-6Al4V is typically less than $10 \%$ at room temperature[43], increasing to about $20 \%$ at $650^{\circ} \mathrm{C}[43]$.Ti- $6242 \mathrm{~S}$ typically contains a smaller amount of beta phase (about $10 \%$ ) at $650^{\circ} \mathrm{C}[41]$. Due to the relatively small amount of beta phase, the observed oxygen rich layer at $650^{\circ} \mathrm{C}$ does not exhibit a characteristic large enrichment of alpha phase near the surface (Figure 12). Furthermore, with increasing oxygen concentration (below beta transus) the 
enrichment of alpha phase is increased[21]. As such, modeling of oxygen ingress during service should account for the various volume fractions of alpha phase, along with retained beta, and the interphase boundaries. To avoid confusion between in service oxygen ingress that leads to enrichment only, and ingress that results in alpha phase evolution, the oxygen rich layer during service at temperatures less than $650^{\circ} \mathrm{C}$ should not be called "alpha case". Herein, the term oxygen-rich layer (ORL) has been used to emphasize the need to use different modeling parameters to simulate oxygen ingress during service.

A more physically meaningful estimate of the upper limit of exposure that may be rightly called an ORL is related to the volume fraction of beta phase in the subsurface region, taking into account the enrichment of alpha phase with oxygen concentration. The work of Liu and Welsch[21] documented the effect of oxygen concentration on the volume fraction of beta for Ti6A14V (Figure 16)by monitoring the change in the volume fraction of beta at different bulk oxygen concentrations. Visual inspection revealed a dramatic increase in the rate of change of beta volume fraction at temperatures higher than $850^{\circ} \mathrm{C}$ (Figure 16). Consequently, that temperature can be the threshold temperature to distinguish between potential alpha case formation and ORL. Similarly, the procedure using the beta approach curve measured using quantitative metallography by Semiatin et al.for Ti-6Al4V[43] and Ti-6424S[41](Figure 17a) can be used to plot the rate of change in the beta volume fraction as a function of temperature, showing a pronounced increase in the rate of changeof beta volume fraction $\left(\mathrm{dVF}_{\beta} / \mathrm{dT}\right)$ above $850-900^{\circ} \mathrm{C}$ for both alloys(Figure $17 \mathrm{~b}$ ). Consequently, temperatures in the range of $850-900^{\circ} \mathrm{C}$ can be chosen as the range to differentiate between alpha case and ORL for Ti-6A14V and Ti6424S. 
Figure 16 - The effect of oxygen on the fraction of alpha and beta phases at different temperatures[21].

Figure 17(a) Beta-approach curve experimentally measured for Ti-6Al4V[43] andTi-6424S[41];(b) the calculated rate of change in the volume fraction of beta as a function of temperature. The critical temperature region for differentiation between alpha case and ORL is indicated.

\section{Conclusions}

The effect of various microstructures of Ti-6Al-2Sn-4Zr-2Mo on oxygen ingress during $650^{\circ} \mathrm{C}$ exposure up to 420 hours was investigated. Texture effects on measurements of oxygen ingress were minimized by producing each microstructure from the same parent material, thus maintaining similarity in texture components between samples. A distinction between the oxygen-rich layer (ORL) formed during service and alpha-case formed during casting was established to aid researchers in distinguishing between a primarily high temperature $\beta$-phase phenomenon causing discontinuity in microstructure between the brittle layer and base material (alpha-case) and theintermediate temperature interaction of diffusion in both $\alpha$ and $\beta$ phases, as well as along interphase boundaries (ORL) with no significant discontinuity in microstructure. A practical protocol to estimate oxygen effective diffusivity in various microstructures was proposed using microhardness measurements and optical microscopy. An oxygen-ingress model was developed to predict the thickness of the ORL. The thickness was used to predict the critical strain for initiating cracks under tensile loading of various microstructures as a function of exposure time. A model predicting the effect of the depth of ORL on fatigue life was established. The following conclusions were reached:

1. An effective diffusion coefficient for a particular microstructure was proven practical for mean-field modeling of the response of the whole microstructure to oxygen ingress instead of modeling each constituent individually.

2. The colony microstructure had the highest effective diffusion coefficient (i.e. thickest ORL) while the basketweave microstructure had the smallest (i.e. thinnest ORL). 
3. In the bimodal microstructures, the effective diffusion coefficient increases with increasing volume fraction of secondary alpha.

4. Using the oxygen ingress model, the critical strain to initiate cracking in the ORL can be predicted as a function of exposure time. These data also enable the estimation of the exposure time necessary for initiation at a given strain for the various microstructures. For example, at a critical strain to initiate cracks of $1.2 \%$, the basketweave microstructure was predicted to survive 4 times longer ( $400 \mathrm{hr}$ ) than the colony microstructure $(100 \mathrm{hr})$ before developing a surface crack at the same temperatures.

5. The addition of crack growth data allows for complete lifing taking into account the initial crack length as a function of ORL thickness (exposure time). In Ti-6424S with colony microstructure, increasing the loading stress from $0.5 \sigma_{Y}$ to $0.7 \sigma_{Y}$ was predicted to decrease fatigue life by $50 \%$ (from $400 \mathrm{hrs}$ to $100 \mathrm{hrs}$ ) during heating at $650^{\circ} \mathrm{C}$ in atmospheric conditions.

\section{Acknowledgement}

This work was performed as part of the in-house research activities of Materials Resources LLC under a SBIR contract from the Air Force Research Laboratory, Materials and Manufacturing Directorate, AFRL/RXCM, Wright-Patterson Air Force Base, OH (Dr. J. Tiley program manager). DPS, JBS, AAS, SRK were supported under SBIR contract FA8650-13-C-5178.

\section{References}

[1] G. Lütjering, J.C. Williams, Titanium, Heidelberg, Springer, 2007, .

[2] M.L. Blosser, Development of Metallic Thermal Protection Systems for the Reusable Launch Vehicle, NASA Langley Technical Report Server, 1996, . 
[3] L.R. Jackson, Multiwall Thermal Protection System. US4344591, 1982.

[4] A.L. Pilchak, W.J. Porter, R. John, Room Temperature Fracture Processes of a near- $\alpha$ Titanium Alloy Following Elevated Temperature Exposure, J. Mater. Sci. 47 (2012) 7235-7253.

[5] A. Jostsons, P. McDougall, Phase Relationships in Titanium-Oxygen Alloys, in: R.I. Jaffee, N.E. Promisel (Eds.), Sci. Technol. Appl. Titan. 1970, pp. 745-763.

[6] C.J. Rosa, Oxygen Diffusion in Alpha and Beta Titanium in the Temperature Range of $932^{\circ}$ to $1142^{\circ} \mathrm{C}$, Metall. Trans. 1 (1970) $2517-2522$.

[7] M.R. Bache, W.J. Evans, H.M. Davies, Electron Back Scattered Diffraction (EBSD) Analysis of Quasi-Cleavage and Hydrogen Induced Fractures under Cyclic and Dwell Loading in Titanium Alloys, J. Mater. Sci. 32 (1997) 3435-3442.

[8] M.W. Mahoney, N.E. Paton, Fatigue and Fracture Characteristics of Silicon-Bearing Titanium Alloys, Metall. Mater. Trans. A 9 (1978) 1497-1501.

[9] D. Rugg, T.B. Britton, J. Gong, A.J. Wilkinson, P.A.J. Bagot, In-Service Materials Support for Safety Critical Applications - A Case Study of a High Strength Ti-Alloy Using Advanced Experimental and Modelling Techniques, Mater. Sci. Eng. A 599 (2014) 166-173.

[10] R. Gaddam, B. Sefer, R. Pederson, M.-L. Antti, Oxidation and Alpha-Case Formation in Ti-6Al-2Sn-4Zr-2Mo Alloy, Mater. Charact. (2015).

[11] L. Liu, Suface Hardening of Titanium Alloys by Gas Phase Nitridation under Kinetic Control. Case Western Reserve University, 2005.

[12] R.J. Wasilewski, G.L. Kehl, Diffusion of Nitrogen and Oxygen in Titanium, J. Inst. Met. 83 (1954).

[13] A. Chen, J. Blanchard, S.W. Han, J.R. Conrad, R.A. Dodd, P. Fetherston, F.J. Worzala, A Study of Nitrogen Ion-Implanted Ti-6ai-4v Eli by Plasma Source Ion Implantation at High Temperature, J. Mater. Eng. Perform. 1 (n.d.) 845-847.

[14] E.S. Metin, O.T. Inal, Microstructural and Microhardness Evaluations in Ion Nitrided Titanium, Mater. Sci. Eng. A 145 (1991) 65-77. 
[15] K.S. Chan, M. Koike, B.W. Johnson, T. Okabe, Modeling of Alpha-Case Formation and Its Effects on the Mechanical Properties of Titanium Alloy Castings, Metall. Mater. Trans. A 39 (2008) 171-180.

[16] T.A. Parthasarathy, W.J. Porter, S. Boone, R. John, P. Martin, Life Prediction under Tension of Titanium Alloys That Develop an Oxygenated Brittle Case during Use, Scr. Mater. 65 (2011) 420-423.

[17] C.E. Shamblen Redden, Air Contamination and Embrittlement of Titanium Alloys, in: R.I. Jaffee, N.E. Promisel (Eds.), Sci. Technol. Appl. Titan. Pergamon Press, 1970, pp. 199208.

[18] K.S. Mcreynolds, S. Tamirisakandala, A Study on Alpha-Case Depth in Ti-6Al-2Sn-4Zr2Mo, Metall. Mater. Trans. A 42 (2011) 1732-1736.

[19] P. Shewmon, Diffusion in Solids, 2nd ed., TMS, 1989, .

[20] R.A. Brockman, A.L. Pilchak, W. John Porter Iii, R. John, Estimation of Grain Boundary Diffusivity in near- $\alpha$ Titanium Polycrystals, Scr. Mater. 65 (2011) 513-515.

[21] Z. Liu, G. Welsch, Literature Survey on Diffusivities of Oxygen, Aluminum, and Vanadium in Alpha Titanium, Beta Titanium, and in Rutile, Metall. Trans. A 19 (1988) $1121-1125$.

[22] J. Tiley, J. Shaffer, A. Shiveley, A. Pilchak, A. Salem, The Effect of Lath Orientations on Oxygen Ingress in Titanium Alloys, Metall. Mater. Trans. A 45 (2014) 1041-1048.

[23] S.L. Semiatin, V. Seetharaman, I. Weiss, Hot Working of Titanium Alloys--An Overview, Adv. Sci. Technol. Titan. Alloy Process. (1996) 3-73.

[24] C. Oskay, M. Haney, Computational Modeling of Titanium Structures Subjected to Thermo-Chemo-Mechanical Environment, Int. J. Solids Struct. 47 (2010) 3341-3351.

[25] I. Gurappa, Prediction of Titanium Alloy Component Life by Developing an Oxidation Model, J. Mater. Sci. Lett. 22 (2003) 771-774.

[26] J.W. Hutchinson, Z. Suo, Mixed Mode Cracking in Layered Materials, Adv. Appl. Mech. 
29 (1992) 191.

[27] M.D. Thouless, E. Olsson, A. Gupta, Cracking of Brittle Films on Elastic Substrates, Acta Metall. Mater. 40 (1992) 1287-1292.

[28] D. Eylon, S. Fujishiro, P.J. Postans, F.H. Froes, High-Temperature Titanium Alloys - a Review, JOM 36 (1984) 55-62.

[29] K. McReynolds, S. Tamirisakandala, A Study on Alpha-Case Depth in Ti-6Al-2Sn-4Zr2Mo, Metall. Mater. Trans. A 42 (2011) 1732-1736.

[30] ASTM E384-11e1, Standard Test Method for Knoop and Vickers Hardness of Materials, West Conshohocken, PA, 2011, .

[31] K.S. Chan, M. Koike, B.W. Johnson, T. Okabe, Modeling of Alpha-Case Formation and Its Effects on the Mechanical Properties of Titanium Alloy Castings, Metall. Mater. Trans. A 39 (2008) 171-180.

[32] F. Pitt, M. Ramulu, Influence of Grain Size and Microstructure on Oxidation Rates in Titanium Alloy Ti-6Al-4V under Superplastic Forming Conditions, J. Mater. Eng. Perform. 13 (2004) 727-734.

[33] R.N. Shenoy, J. Unnam, R.K. Clark, Oxidation and Embrittlement of Ti-6Al-2Sn-4Zr2Mo Alloy, Oxid. Met. 26 (1986) 105-124.

[34] L. Bendersky, A. Rosen, The Effect of Exposure on the Mechanical Properties of the Ti6Al-4v Alloy, Eng. Fract. Mech. 20 (1984) 303-311.

[35] S. Ghosh, M. Mills, S. Rokhlin, V. Sinha, W. Soboyejo, J. Williams, The Evaluation of Cold Dwell Fatigue in Ti-6242, 2007, .

[36] O. Jin, S. Mall, Effects of Microstructure on Short Crack Growth Behavior of Ti-6Al-2Sn4Zr-2Mo-0.1Si Alloy, Mater. Sci. Eng. A 359 (2003) 356-367.

[37] T.L. Anderson, Fracture Mechanics: Fundamentals and Applications, Boca Raton, CRC Press, 2005, .

[38] K.L. Johnson, Contact Mechanics, Cambridge, Cambridge University Press, 1987, . 
[39] A.C. Fischer-Cripps, Nanoindentation, Springer New York, 2004, .

[40] MRL, Ti-Seg, accessed 19 Oct. 2015. URL: http://icmrl.com/software/tiseg.html.

[41] S.L. Semiatin, T.M. Lehner, J.D. Miller, R.D. Doherty, D.U. Furrer, Alpha/beta Heat Treatment of a Titanium Alloy with a Nonuniform Microstructure, Metall. Mater. Trans. A 38 (2007) 910-921.

[42] J.L. Murray, Phase Diagrams of Binary Titanium Alloys, ASM Int. 1987, (1987) 354.

[43] S.L. Semiatin, S.L. Knisley, P.N. Fagin, D.R. Barker, F. Zhang, Microstructure Evolution during Alpha-Beta Heat Treatment of Ti-6Al-4V, Metall. Mater. Trans. A 34 (2003) 2377-2386. 


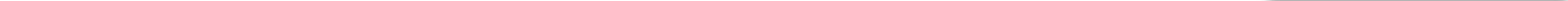




\section{Fig. 1}
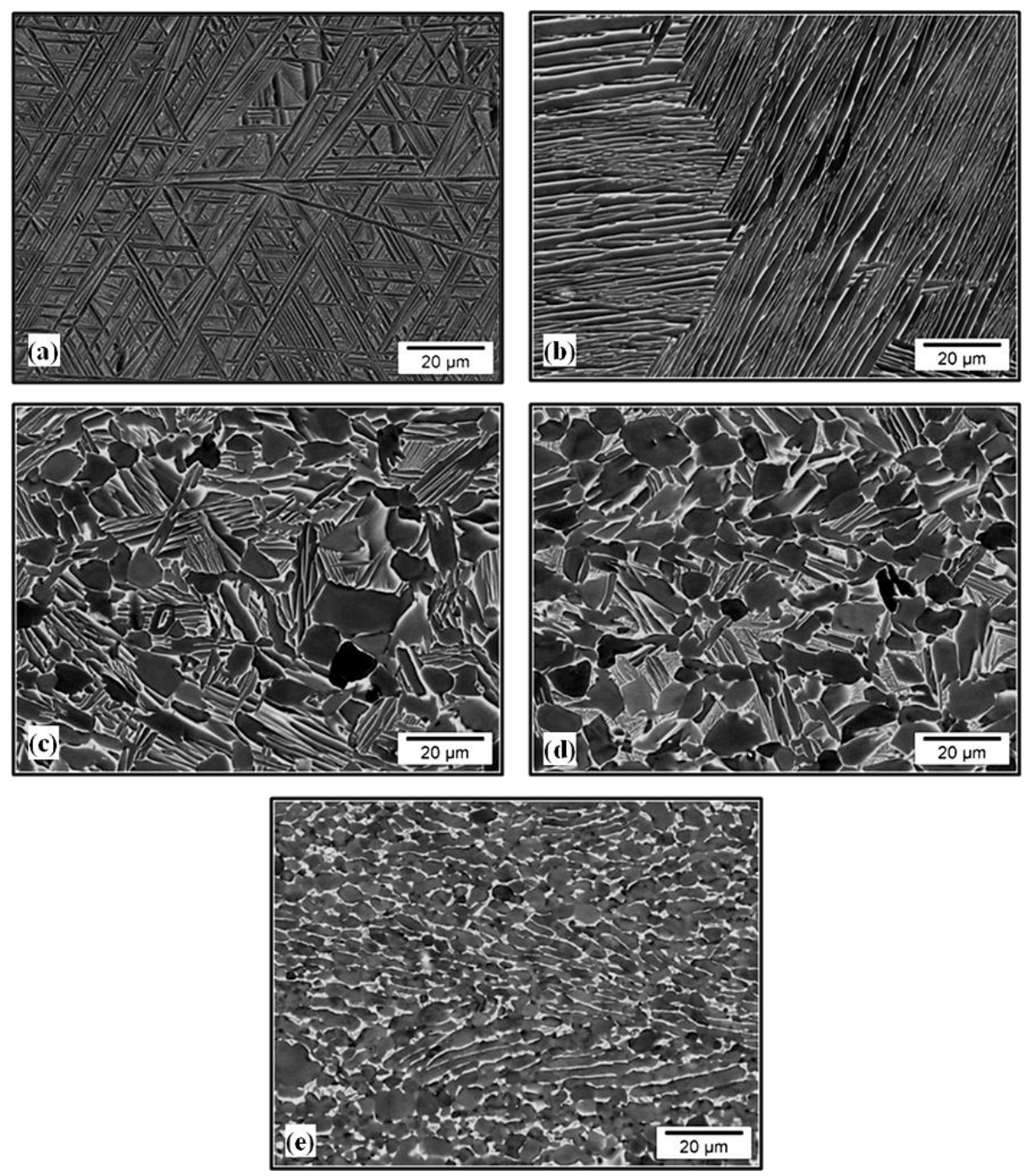

Figure 1- Backscattered electron images of Ti $6242 \mathrm{~S}$ with various microstructures: (a) Basketweave, (b) Colony, (c) Bimodal ( 35\% ap), (d) Bimodal ( $\sim 5 \% \alpha p$ ), and (e) Mill-annealed ( $85 \% \alpha p$ ). 


\section{Fig 2}
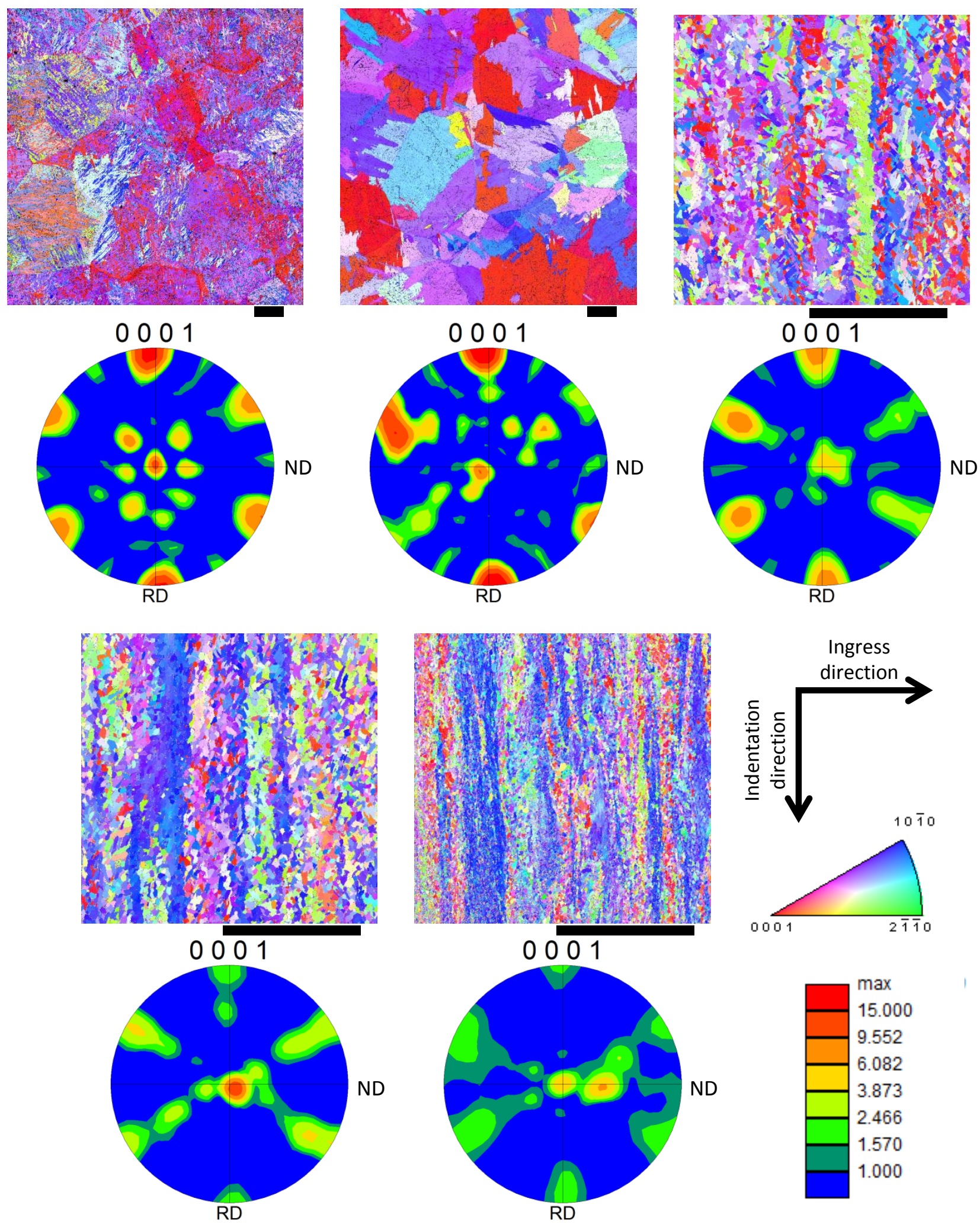

Figure 2 - Inverse pole-figure maps and pole-figure data from EBSD for Ti 6242S with various microstructures: (a) Basketweave, (b) Colony, (c) Bimodal I( 35\% $\alpha$ ), (d) Bimodal II( 45\% ap), and (e) Mill-annealed ( 85\% $\alpha p)$. Inverse pole figure maps are displayed along the indentation (rolling) direction. The length of the scale bar is $250 \mu \mathrm{m}$. 


\section{Fig 3}

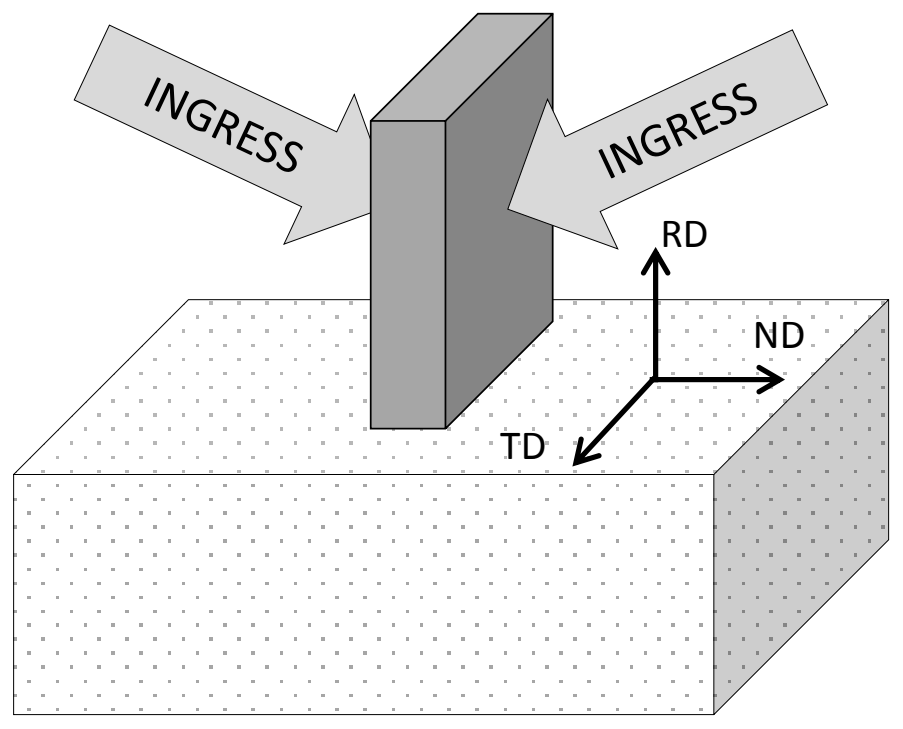

Figure 3 - Positioning of sample coupons during thermal exposure. The labels RD, TD, and ND denote the rolling, transverse, and normal directions of the sheet, respectively. 
Fig 4

\section{ORL}

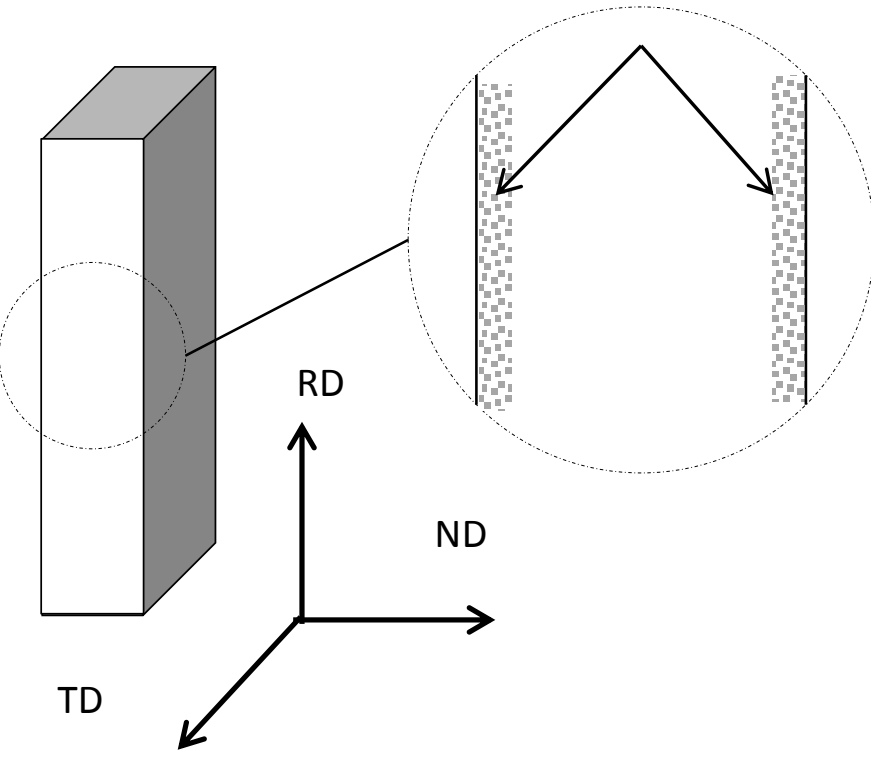

Figure 4 - Sectioning coupons for characterization of ORL depth 


\section{Fig 5}

(a)

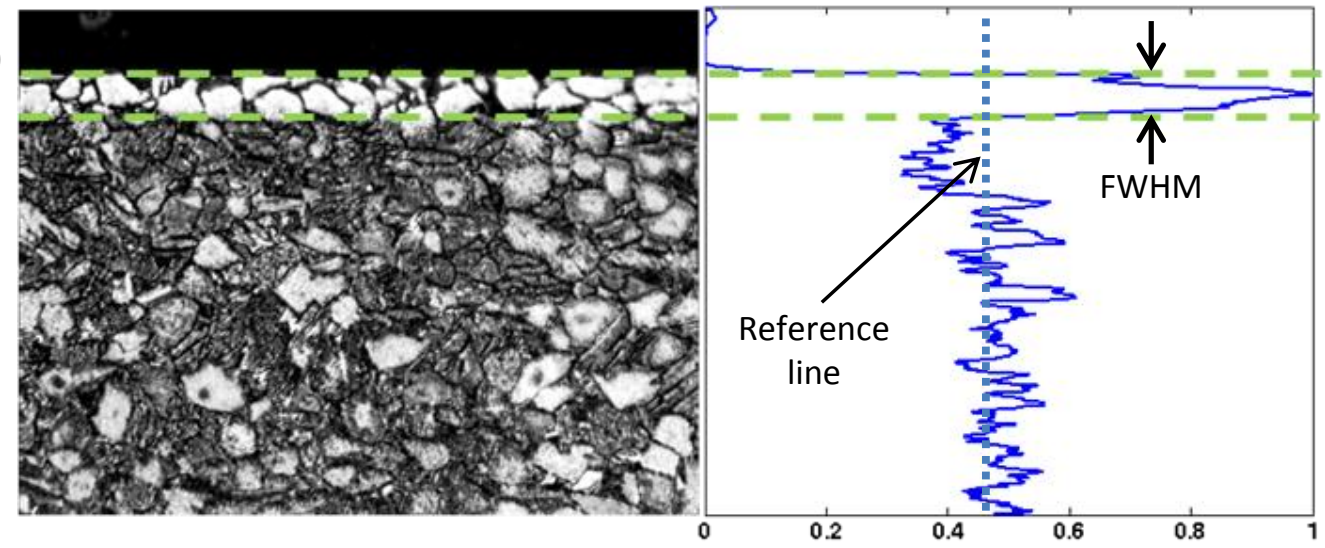

(b)

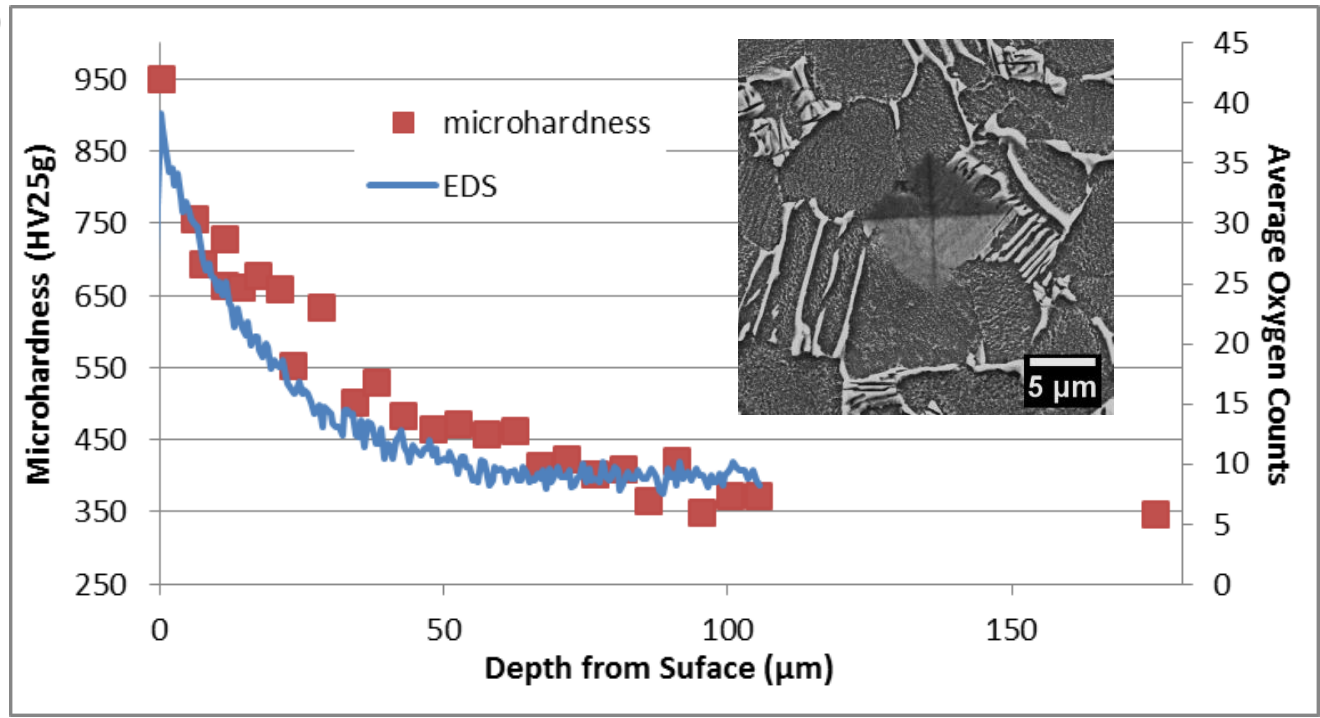

Figure 5 - Measuring Oxygen Ingress Depth: (a) Optical microscopy using FWHM of the Depth-Sensitive Histogram (b) Microhardness Indentation. 


\section{Fig 6}
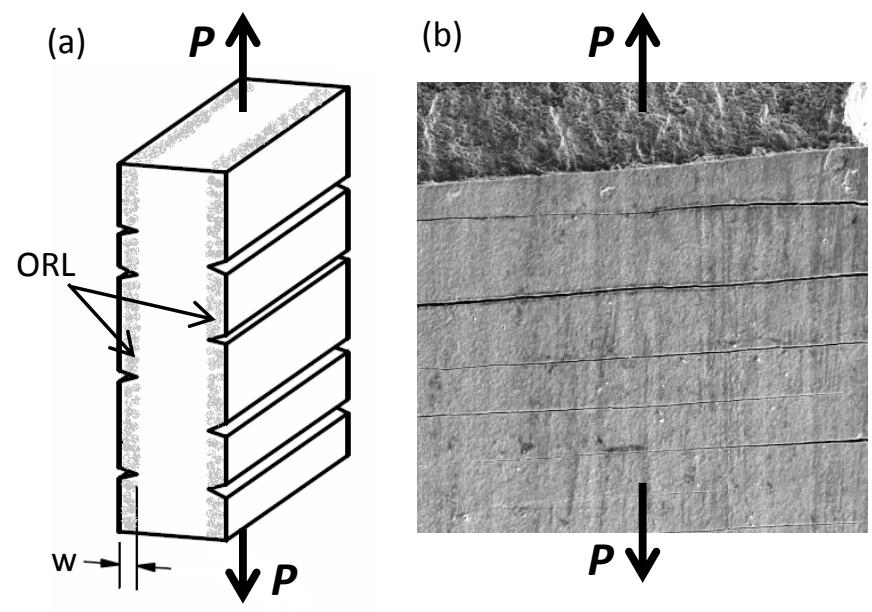

Figure 6 (a) Schematic of surface cracks in the brittle ORL under tensile loading; (b) Secondary electron image showing periodic cracking orthogonal to the loading direction 


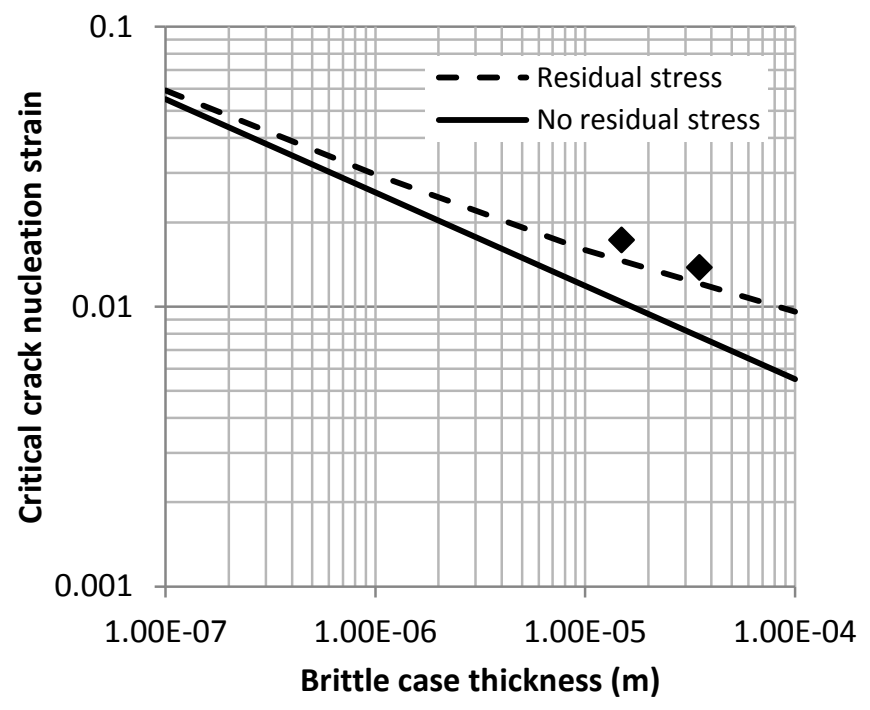

Figure 7. Predicted critical strain to nucleate surface cracks in the ORL under tensile loading. The model parameters and data were obtained from Ref [12]. 


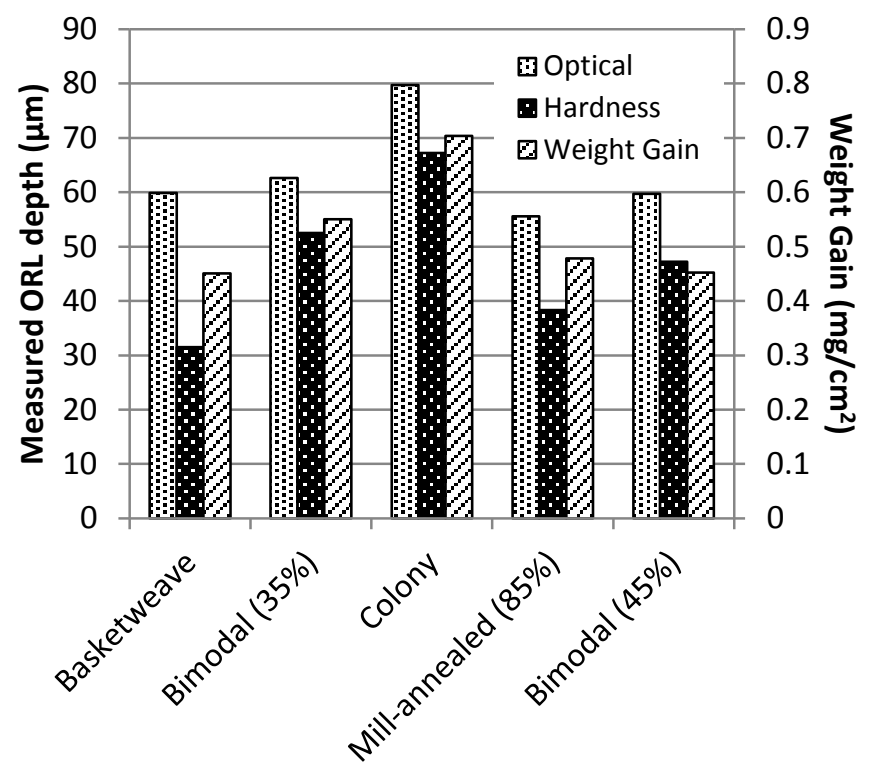

Figure 8 - Comparison of optical and microhardness measurements of ORL thickness with weight-gain data after $420 \mathrm{hr}$ exposure. 


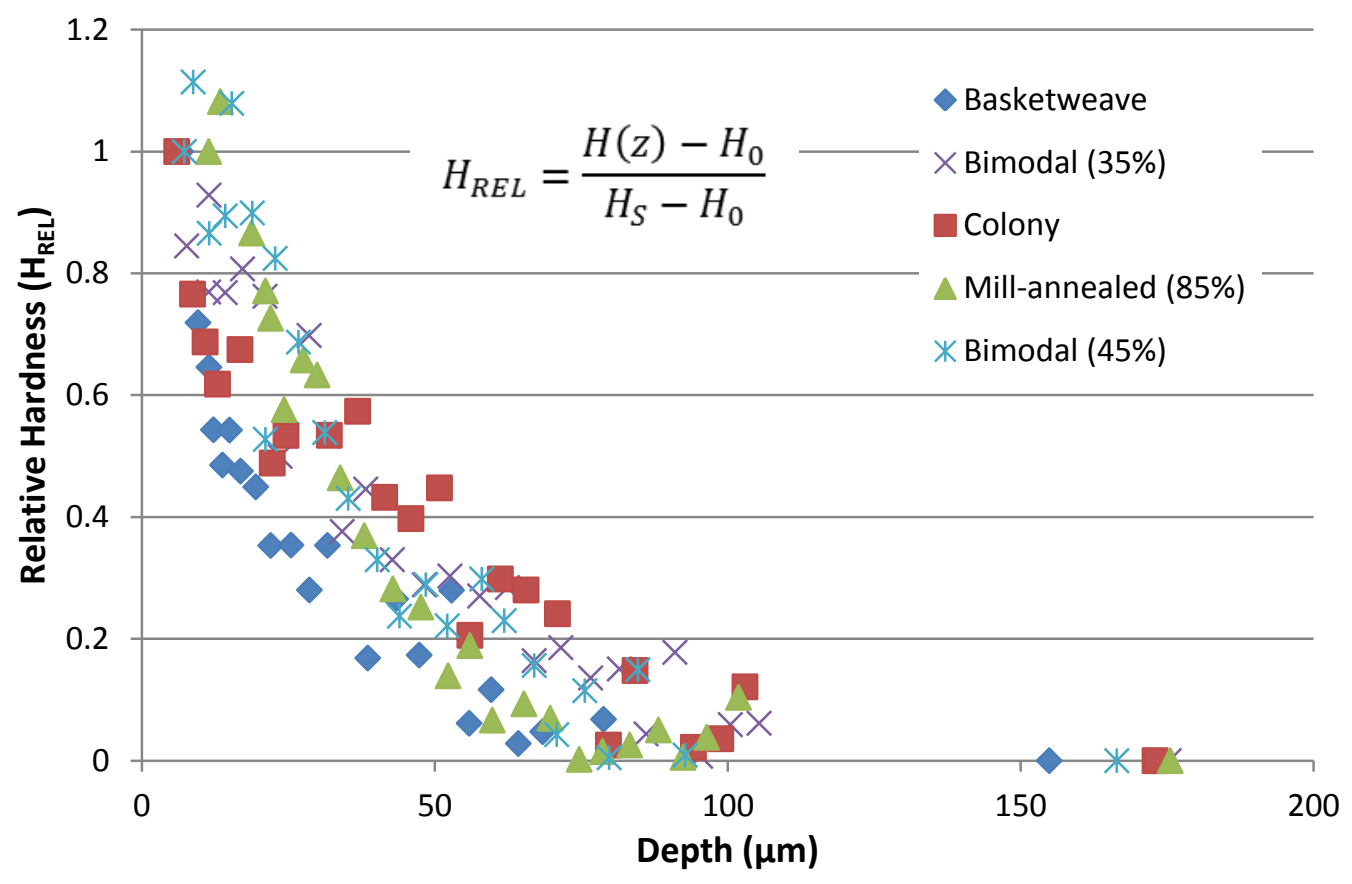

Figure 9. Measured hardness profile for various microstructures, normalized according to Equation 4 to account for variation in base metal hardness between microstructures. 


\section{Fig 10}
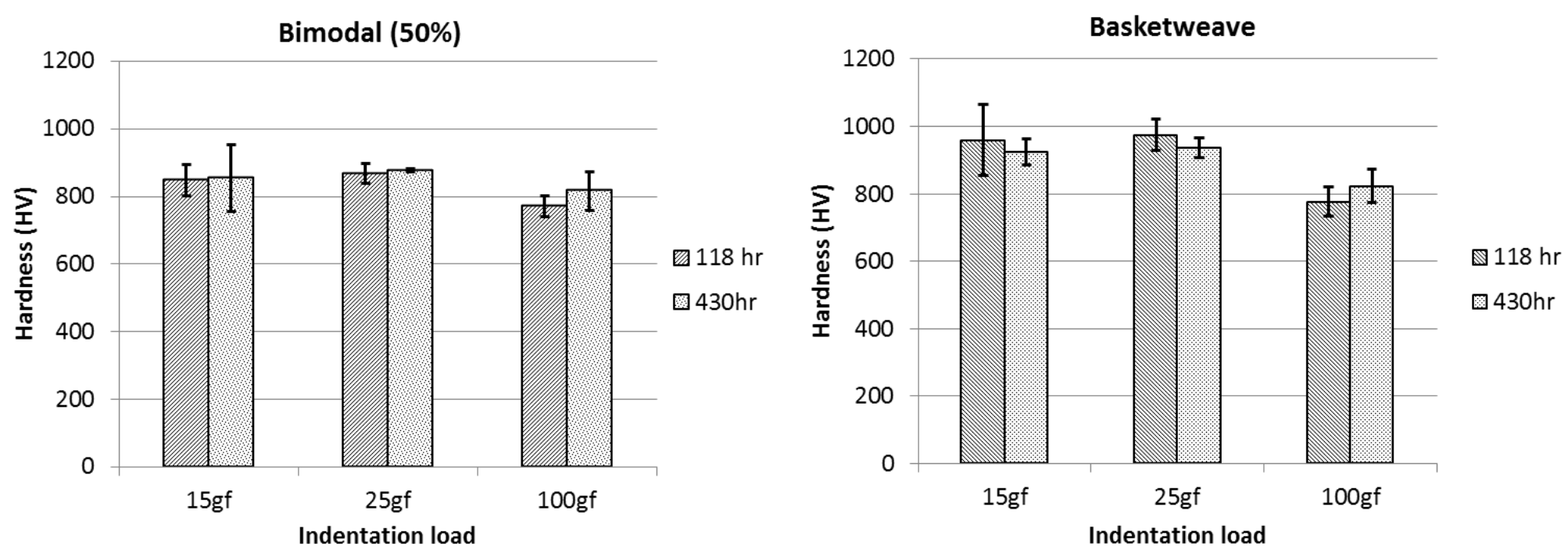

Figure 10 - Indentation hardness measurements under loads of 15gf, 25gf, and 100gf on the exposed surface for the bimodal microstructure with $45 \% \alpha \mathrm{P}$ and the basketweave microstructure. Error bars indicate the standard deviation of 5 duplicate indentations per sample and force. 


\section{Fig 11}

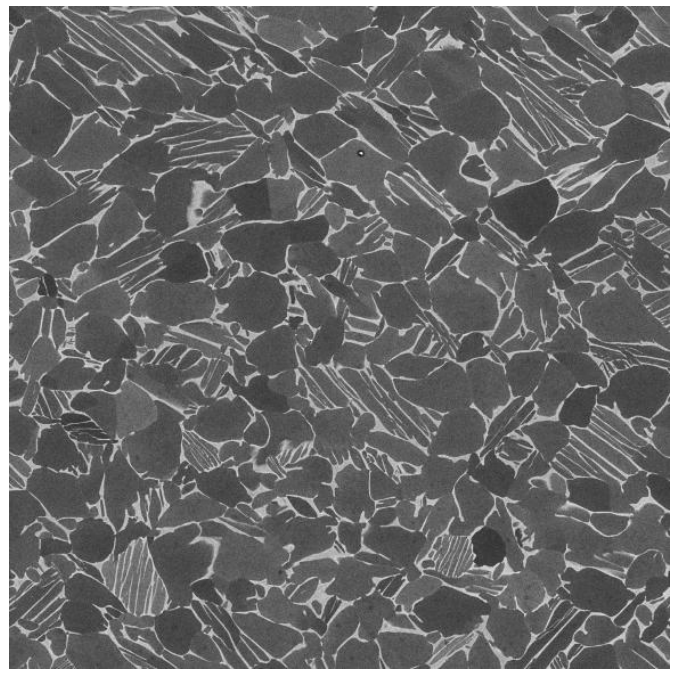

$25 \mu \mathrm{m}$

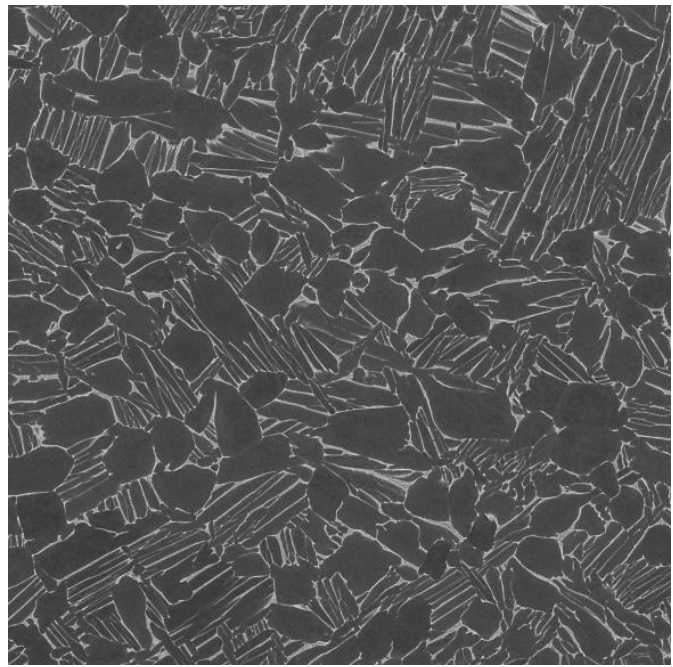

$25 \mu \mathrm{m}$

Figure 11 - BSE images of the microstructure of the bimodal microstructure with 35\% primary alpha as-heat treated (left) and after $4 \mathrm{hr}$ at 650C/WQ (right) showing the stability of microstructure at the exposure temperature 


\section{Fig 12}
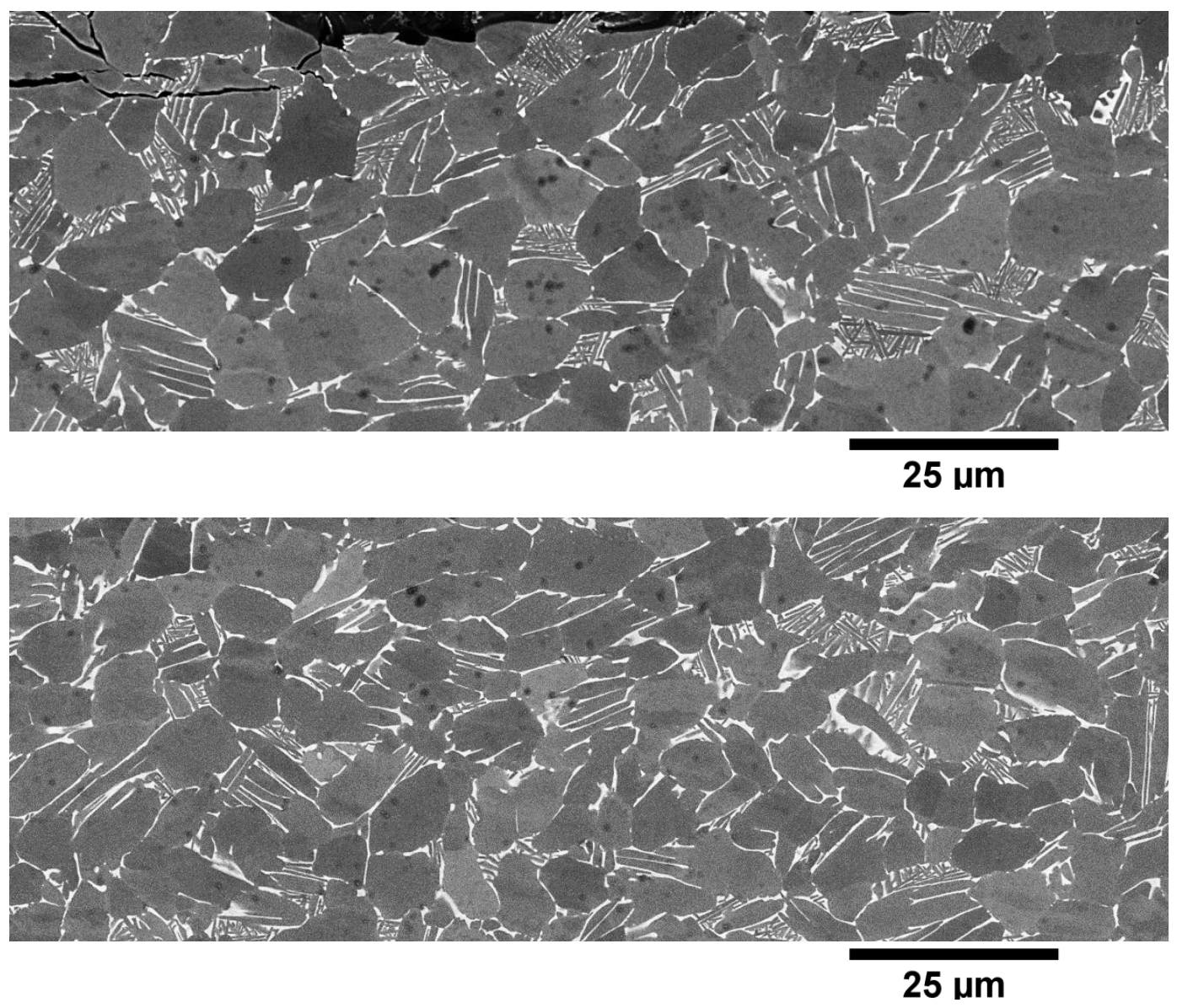

Figure 12 - BSE images of the bimodal microstructure with $45 \%$ primary alpha in the ORL (top) and in the base metal (bottom) after $420 \mathrm{hr}$ at $650^{\circ} \mathrm{C}$ showing the slight increase in primary alpha in the ORL. 


\section{Fig 13}

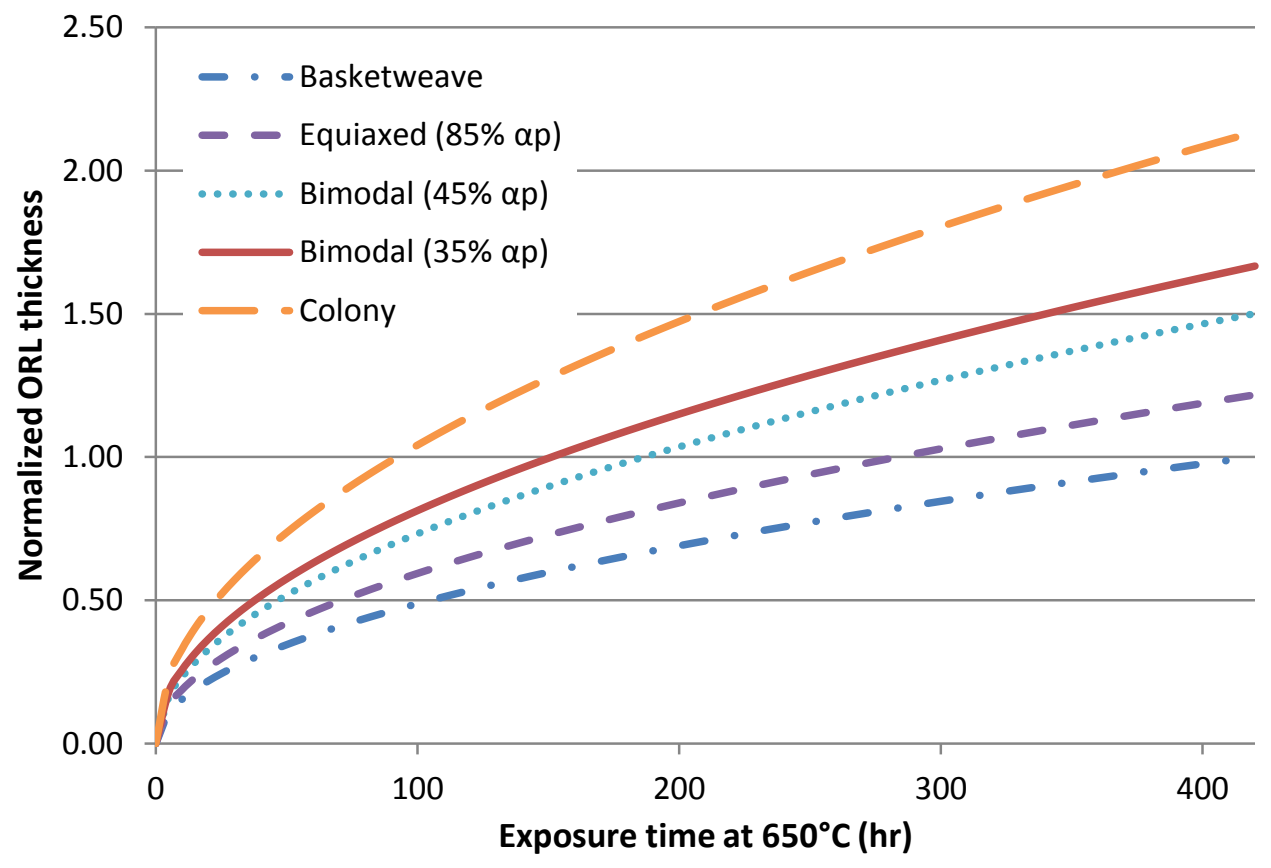

Figure 13 - Normalized predictions of the thickness of the oxygen-rich layer using Fick's second law. 


\section{Fig 14}

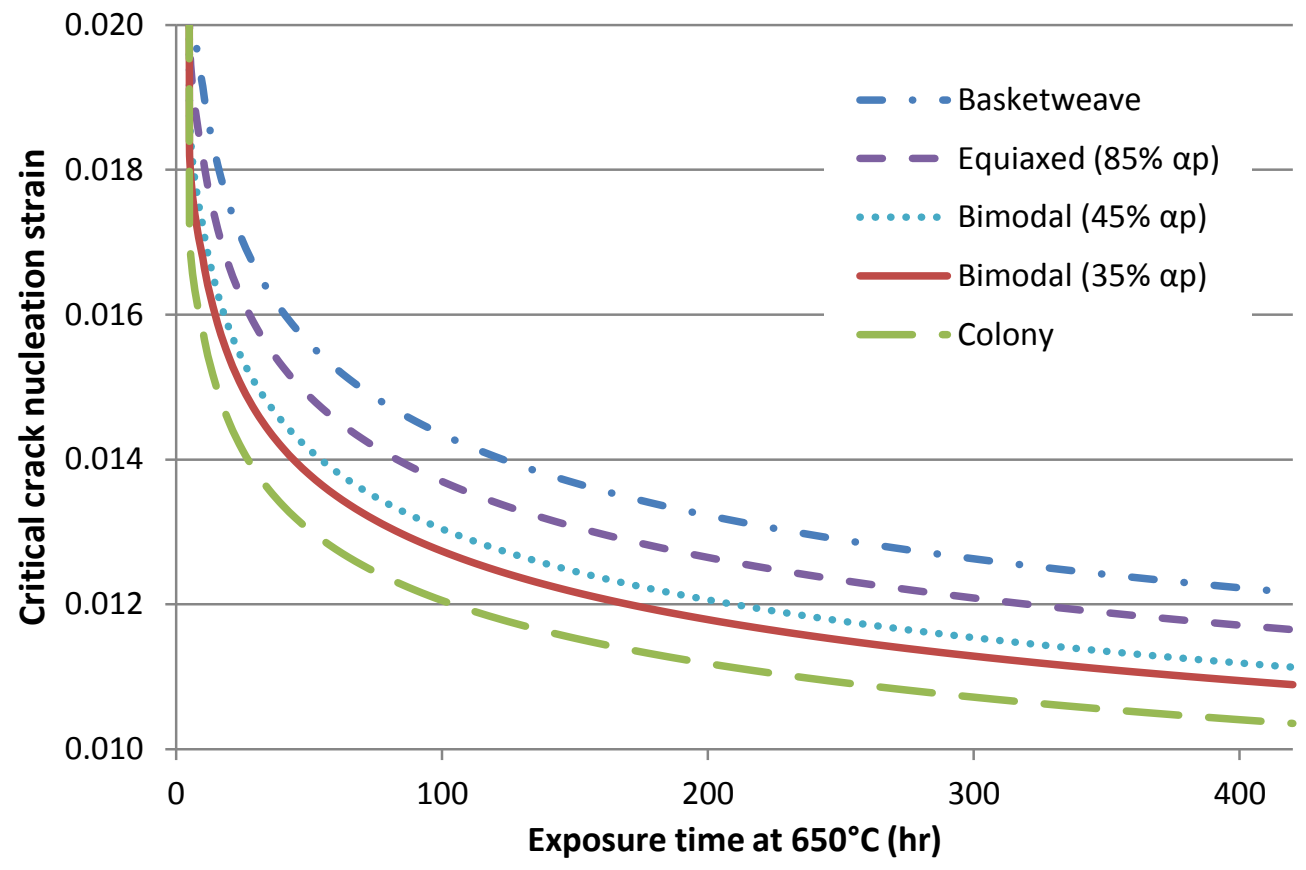

Figure 14. Predicted critical strain for crack nucleation as a function of exposure time at $650^{\circ} \mathrm{C}$ for various microstructures of Ti-6424S. 


\section{Fig 15}

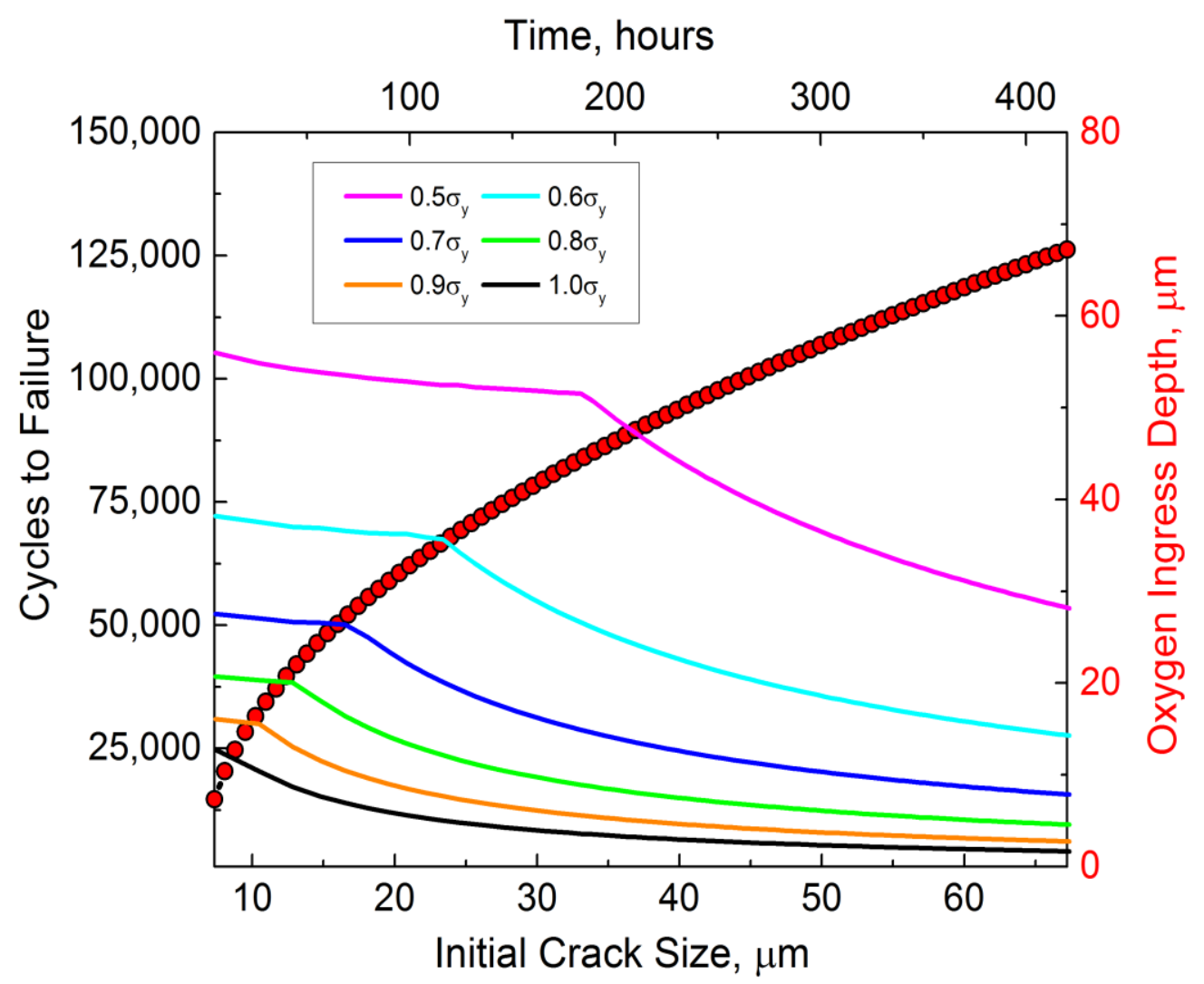

Figure 15. Results from deterministic fatigue crack growth predictions at various stress levels utilizing the oxygen-ingress depth as a function of time for Ti-6424S as the initial crack size. The transition in behavior at smaller crack lengths for each applied stress level is due to the fact that the depth of the crack formed in the oxygen-rich layer did not have sufficient driving force to grow as a long crack and thus small crack effects had to be considered. 


\section{Fig 16}

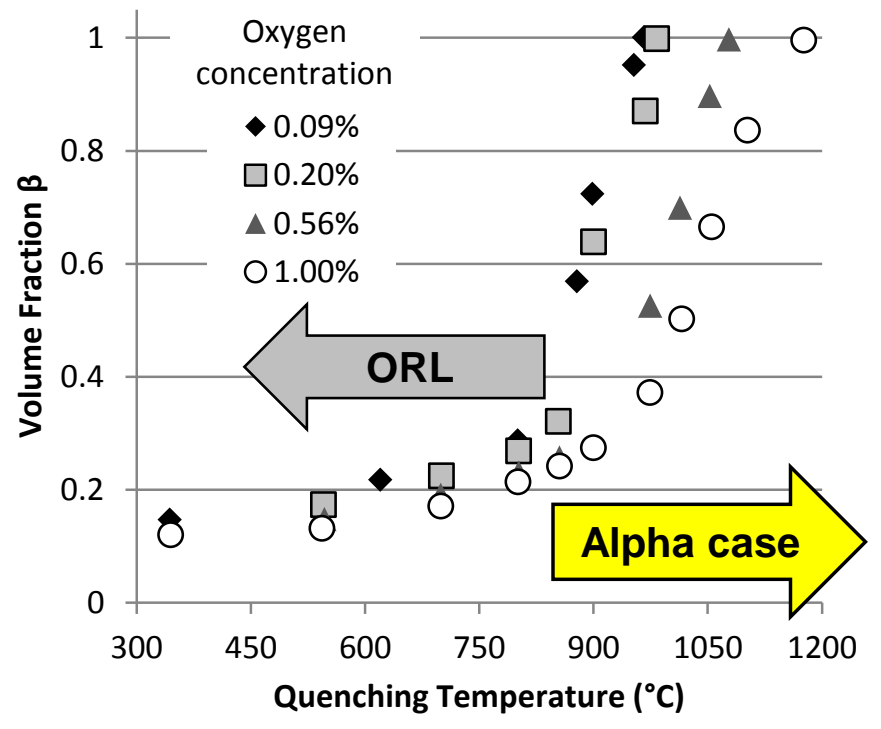

Figure 16. The effect of oxygen on the fraction of alpha and beta phases at different temperatures[17]. 


\section{Fig 17}

(a)

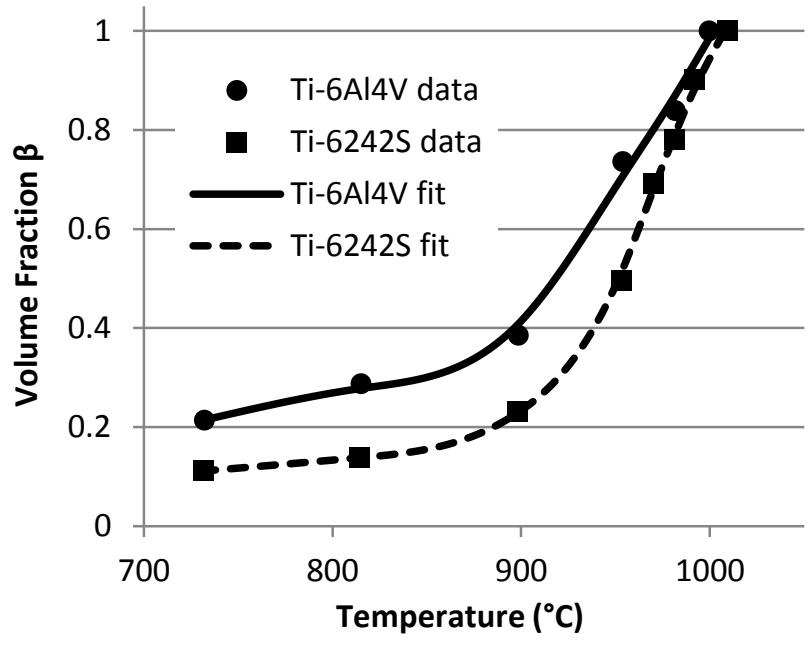

(b)

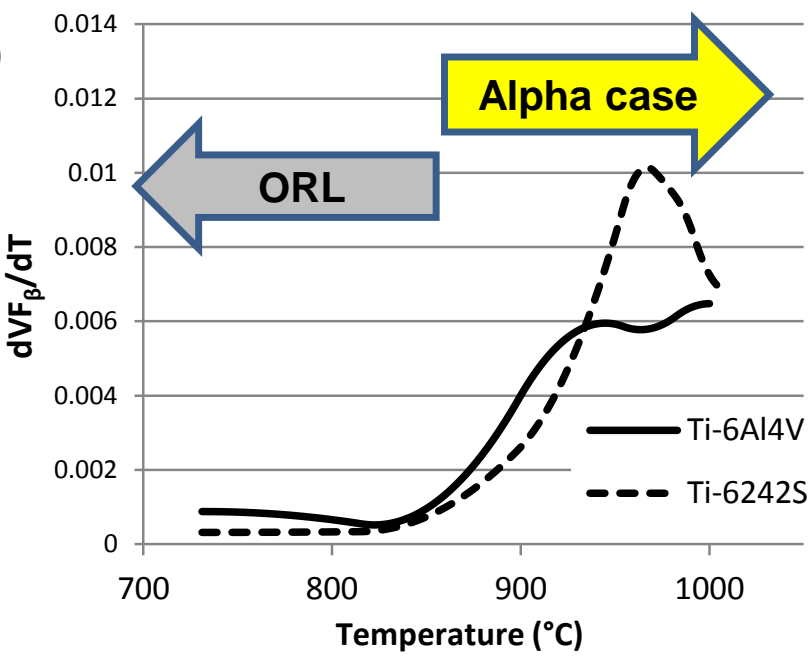

Figure 17 (a) Beta-approach curve experimentally measured for Ti6AI4V[37] andTi-6424S[35]; (b) the calculated rate of change in the volume fraction of beta as a function of temperature. The critical temperature region for differentiation between alpha case and oxygenrich layer is indicated. 